\title{
Review \\ A Mini-Review of Enhancing Ultrafiltration Membranes (UF) for Wastewater Treatment: Performance and Stability
}

\author{
Eman Sh. Awad ${ }^{1,2}$, Tamara M. Sabirova ${ }^{1}$, Natalia A. Tretyakova ${ }^{1}$, Qusay F. Alsalhy ${ }^{3, *(\mathbb{D}, \text { Alberto Figoli }}{ }^{4}$ (D) \\ and Issam K. Salih 5
}

1 Department of Chemical Technology of Fuel and Industrial Ecology, Institute of Chemical Technology, Ural Federal University named after the first President of Russia B.N. Yeltsin, 620002 Yekaterinburg, Russia; eman.erc@gmail.com (E.S.A.); t.m.sabirova@urfu.ru (T.M.S.); n-tretyakova@mail.ru (N.A.T.)

2 Environmental Research Center, University of Technology-Iraq, Baghdad 10066, Iraq

3 Membrane Technology Research Unit, Department of Chemical Engineering, University of Technology-Iraq, Baghdad 10066, Iraq

4 Institute on Membrane Technology, National Research Council (ITM-CNR), 87030 Rende, Italy; a.figoli@itm.cnr.it

5 Department of Chemical Engineering and Petroleum Industries, AlMustaqbal University College, Babylon 51001, Iraq; Dr_IssamKamil@mustaqbal-college.edu.iq

* Correspondence: 80006@uotechnology.edu.iq

check for updates

Citation: Awad, E.S.; Sabirova, T.M.; Tretyakova, N.A.; Alsalhy, Q.F.; Figoli, A.; Salih, I.K. A Mini-Review of Enhancing Ultrafiltration Membranes (UF) for Wastewater Treatment: Performance and Stability. ChemEngineering 2021, 5, 34. https:// doi.org/10.3390/chemengineering 5030034

Academic Editor: Changhyun Roh

Received: 29 April 2021

Accepted: 28 June 2021

Published: 1 July 2021

Publisher's Note: MDPI stays neutral with regard to jurisdictional claims in published maps and institutional affiliations.

Copyright: (C) 2021 by the authors. Licensee MDPI, Basel, Switzerland. This article is an open access article distributed under the terms and conditions of the Creative Commons Attribution (CC BY) license (https:/ / creativecommons.org/licenses/by/ $4.0 /)$.

\begin{abstract}
The scarcity of freshwater resources in many regions of the world has contributed to the emergence of various technologies for treating and recovering wastewater for reuse in industry, agriculture, and households. Deep wastewater treatment from oils and petroleum products is one of the difficult tasks that must be solved. Among the known technologies, UF membranes have found wide industrial application with high efficiency in removing various pollutants from wastewater. It is shown that the search for and development of highly efficient, durable, and resistant to oil pollution UF membranes for the treatment of oily wastewater is an urgent research task. The key parameters to improve the performance of UF membranes are by enhancing wettability (hydrophilicity) and the antifouling behavior of membranes. In this review, we highlight the using of ultrafiltration (UF) membranes primarily to treat oily wastewater. Various methods of polymer alterations of the UF membrane were studied to improve hydrophilicity, the ability of antifouling the membrane, and oil rejection, including polymer blending, membrane surface modification, and the mixed membrane matrix. The influence of the type and composition of the hydrophilic additives of nanoparticles (e.g., Multiwall carbon nanotubes (MWCNT), graphene oxide (GO), zinc oxide (ZnO), and titanium dioxide $\left(\mathrm{TiO}_{2}\right)$, etc.) was investigated. The review further provides an insight into the removal efficiency percent.
\end{abstract}

Keywords: UF membrane; nanoparticle additive; performance membrane; modification; oily wastewater

\section{Introduction}

The sustainable utilization of water resources is the mainstay for the sustainable development of modern society and the economy. As a result of the rapid development of the economy and society, the pressure on the shortage of water resources has increased due to industrial and human activities which consequently discharge most of their pollutants into the environment as sewage, waste, accidental discharges, etc. [1,2].

Various technologies have appeared to clean and restore polluted water for industrial, agricultural, and human consumption, such as screening, pre-sedimentation, coagulationflocculation, advanced oxidation processes (AOPs), and the filter membrane [3], as well as numerous techniques for the wastewater purification, containing conventional physical, chemical, biological, and membrane-based methods [4,5]. Advanced oxidation processes (AOPs) are an excellent technique for treating the contaminated wastewaters containing 
organic pollutants. The biggest drawback of the AOP is its costs; the most significant are the operating and maintenance costs, which are relatively high compared to other techniques. Moreover, it is a complex chemistry tailored to specific pollutants, and the removal of residual peroxide may need to be considered [6]. The UF membrane has emerged in a wide range of industrial applications with high removal efficiency of pollutants of the wastewater especially oily wastewater; therefore, it is more effective than the other techniques employed such as AOPs. Membranes are prepared from inorganic materials (such as ceramics) and organic materials (such as polymers). Current research focuses on polymeric membranes owing to higher flexibility, best control of the mechanism of pore forming, required smaller spaces for installation, and inexpensive implementation compared to the brittle material of inorganic membranes [7].

One of the major challenges is permeate flux decline owing to fouling of the membrane (which is caused when the water contaminants stick to the membrane's surface or pass through its structure, thus reducing the membrane's performance) during the filtration process, which can be improved substantially by developing hydrophilic membranes; this could result in less oily contaminants adhering to the membrane surface, less membrane fouling, and improved water permeability $[8,9]$. Several researchers have tried to reduce the fouling phenomenon and enhance the hydrophilicity and performance of polymeric membranes by incorporating various nanoparticles additives (e.g., multiwall carbon nanotubes (MWCNT), graphene oxide (GO), magnesium oxide $(\mathrm{MgO})$, zinc oxide $(\mathrm{ZnO})$, and titanium dioxide $\left(\mathrm{TiO}_{2}\right)$, etc), which allows control with a higher degree on the ability to produce the required structure and reduce fouling of the membrane [4].

This article provides an overview of published research results on improving membrane properties by adding hydrophilic nanoparticles to them, as well as assessing their effect on the performance of UF membranes. In addition, the use of UF membranes for the treatment of oily wastewater is discussed in this review.

Previous reviews briefly highlight on a specific topic without expanding to study other related matters, as they had studied membrane formation, manufacturing procedures, installation techniques, or fouling membranes $[8,10,11]$. Therefore, this review dealt with more than one topic; it highlights the UF membranes' manufacturing by the addition types of nanoparticles, which greatly affect the performance of the membrane; the development of membrane technology such as surface modification; as well as the synthesis techniques used.

\section{Polymeric Membranes}

Every polymeric material has specified properties, making them suitable for the preparation of different membranes for the application of various separation processes. In the last decade, researchers have focused their studies on using the polymeric membranes for a wide range of applications due to better pore-forming control, easy-forming properties, and inexpensive implementation to that of ceramic-based membranes as well as outstanding mechanical properties, good chemical resistance, and low energy requirements [7].

The polymeric materials such as polyvinylidene fluoride (PVDF) $[2,9,12-17]$, polyethersulfone (PES) [18-21], polysulfone (PSf) [22-25], polyvinyl chloride (PVC) $[2,9,17,20,26]$, and polyacrylonitrile (PAN) [27-29] have been employed to fabricate UF membranes for the application of wastewater treatment. For example, Salahi et al. reported on two types of preparation polymeric membranes for the treatment of oily wastewater (outlet wastewater of the API unit), such as the PES/PVP and PAN UF membrane [18,27]. PVDF membranes were fabricated for treatment of oily wastewater as a result of its well toughness, high mechanical strength, and outstanding chemical stability [12]. Zhang et al. prepared the PVDF membrane to separate oil/water emulsions effectively [13], and Zhang et.al. prepared PVDF/ $\mathrm{ZnO}$ membranes by coated and blending $\mathrm{ZnO}$ nanoparticles with PVDF solution [14]. Moreover, Shi et al. fabricated a modified $\mathrm{PVDF} / \mathrm{TiO}_{2}$ membrane for oil/water emulsions separation [15]. Moreover, Yuan et al. fabricated PVDF-AH membranes by coating the membrane surface with hydrogel to separate oil/water emulsion and 
determined its superior performance [30], whereas Ahmed et al. fabricated a PVDF-HFP membrane modified with cellulose to achieve a membrane with super hydrophilicity and efficiency in oil/water separation [16].

Polymeric membranes have disadvantages, such as disability to separate volatile compounds and the fouling phenomenon at the surface of the membrane that leads to reducing the permeation flux, especially for oily wastewater treatment [10]. In this regard, several approaches were conducted to improve hydrophilicity and antifouling membrane ability, long lifetimes, and oil rejection [31] by developed methods of polymer alterations which include (i) polymer-blending, (ii) membrane surface modification, and (iii) the mixed membrane matrix. Table 1 summarizes approaches for the polymeric membrane for oily wastewater treatment.

\subsection{Polymer Blending}

In the polymer-blending, several types of polymers are mixed together to produce miscible or immiscible dope solution. The blending approach was extensively utilized in polymeric membrane preparation owing to its ability to modify the properties of the membrane, and its versatility to integrate desired properties on the membrane [2]. The aim of the polymer-blending was used to enhance the final structural morphology, wettability, fouling resistance, and functionality of the membrane in order to improve water flux, antifouling properties, and the oil rejection rate [31].

In Masuelli et al.'s work, improvement of the PVDF/sulfonated polycarbonate (SPC) membrane was investigated. The blend-charged membranes were prepared by treating the polycarbonate with acetyl sulphate, then blended SPC with $5 \mathrm{wt} \%$ PVP and $15 \mathrm{wt} \%$ PVDF polymer at $50^{\circ} \mathrm{C}$. By using a film extensor, the finished mixture was cast onto the non-woven support. Membranes are then preserved in a water bath until they are needed. The different SPC/PVDF ratios and its oil rejection coefficient $(R)$ for blend membranes are shown in Table 2. Whereas the resulting membrane had a high oil rejection efficiency $(>96.63 \%)$, the fouling resistance reduced in membranes when it was prepared by using 2 to $4 \mathrm{wt} . \%$ SPC. The SEM microphotographs of the membranes are shown in Figure 1, which shows that SPC has a minor effect on the structure of the membrane: in the presence of SPC, the porous substructure densifies [32].

In the other study, Zhu et al. prepared superhydrophilic zwitterionic PVDF/PSH [poly (3-(N-2-methacryloxyethyl-N, N-dimethyl) ammonato propane sultone)-co-2-hydroxyethylmethacrylate] by using non-solvent induced phase inversion (NIPS). A copolymer poly (dimethylaminoethyl methacrylate-co-2-hydroxyethyl methacrylate) (PDH) was created as a zwitterionic polymer precursor and employed as an additive in membrane preparation to make this zwitterionic PVDF membrane. PVDF and PDH were blended in n-methyl2-pyrrolidone (NMP). The former and the latter have fluxes of 3850 and $6350 \mathrm{~L} / \mathrm{m}^{2} \mathrm{~h}$, respectively. The blending membrane PVDF/PSH showed super hydrophilicity and superoleophobicity due to the presence of zwitterionic sulfonate groups on the membrane layer. Furthermore, the membrane has the flux recovery of $98 \%$ [33]. 
Table 1. Examples of research on the polymer alterations approaches for the polymeric membrane for oily wastewater treatment.

\begin{tabular}{|c|c|c|c|c|c|c|c|c|}
\hline \multirow[b]{2}{*}{ Membrane } & \multirow{2}{*}{$\begin{array}{l}\text { Fabrication } \\
\text { Method }\end{array}$} & \multicolumn{3}{|c|}{ Properties } & \multirow[b]{2}{*}{ Operating Condition } & \multicolumn{2}{|c|}{ Performance } & \multirow[b]{2}{*}{ Ref. } \\
\hline & & Pore Size, nm & Porosity, \% & Contact Angle ${ }^{\circ}$ & & $\begin{array}{c}\text { Oil Rejection } \\
\%\end{array}$ & $\begin{array}{l}\text { Water Flux } \\
\text { (LMH) }\end{array}$ & \\
\hline PVDF/SPC & Polymer-blending & $46.06-35.89$ & - & - & $\begin{array}{c}\text { pressures }=20-100 \mathrm{kPa} \\
\mathrm{pH}=7\end{array}$ & 96.63 & - & [32] \\
\hline $\begin{array}{l}\text { PVDF/Zwitterionic } \\
\text { Polyelectrolyte }\end{array}$ & Polymer-blending & - & - & - & - & 98.00 & 6350.00 & [33] \\
\hline $\begin{array}{l}\text { hydrophilic (PAI)-sulfonated } \\
\text { poly (ether ether keton) }\end{array}$ & Polymer-blending & 81.00 & $79.00 \%$ & $58^{\circ}$ & $\begin{array}{l}\text { Operating time: } 5 \mathrm{~h} \text {, } \\
\text { pressure: } 400.00 \mathrm{kPa} \text {, } \\
\text { temperature: } 25^{\circ} \mathrm{C}\end{array}$ & 95.00 & - & [34] \\
\hline PSf/PEG/PVP & Polymer-blending & $3.00-3.88$ & - & - & $\begin{array}{c}\text { Press. }=68.90-137.90 \mathrm{kPa} \\
\mathrm{pH}=5-8\end{array}$ & 90.00 & - & [22] \\
\hline PAN & Surface modified & - & $71.7-79.6$ & - & - & 85.00 & 2270.00 & [28] \\
\hline $\mathrm{PVDF} / \mathrm{PVA} / \mathrm{TiO}_{2}$ & $\begin{array}{l}\text { Surface modified } \\
\text { (coating) }\end{array}$ & $1.95-3.68$ & 83.00 & $46.05-57.07^{\circ}$ & - & 91.50 & - & [35] \\
\hline PNIPAAm/PPEGMA & $\begin{array}{l}\text { Surface modified } \\
\text { (grafting) }\end{array}$ & - & - & & - & 97.00 & - & [36] \\
\hline PVDF & $\begin{array}{l}\text { Surface modified } \\
\text { (grafting) }\end{array}$ & - & - & & - & 98.00 & - & [37] \\
\hline $\mathrm{PSf} / \mathrm{SiO}_{2}$ & MMM & $36.21-127.20$ & - & - & - & - & 17.32 & [23] \\
\hline $\mathrm{PVDF} / \mathrm{LiCl} \cdot \mathrm{H}_{2} \mathrm{O} / \mathrm{SiO}_{2}$ & MMM & $14.93-34.05$ & $63.26-85.41$ & - & pressure $=0.10 \mathrm{MPa}$ & $62.56-98.83$ & 82.50 & [38] \\
\hline $\mathrm{PVDF} / \mathrm{PVP} / \mathrm{TiO}_{2}$ & MMM & $94.30-104.40$ & $84.10-88.60$ & $68.40-75.70^{\circ}$ & Temperature: $25^{\circ} \mathrm{C}$ & 99.70 & 70.48 & [39] \\
\hline PVDF/PVP & MMM & - & - & - & - & 99.70 & 70.48 & {$[40]$} \\
\hline
\end{tabular}


Table 2. The Weight percent relation SPC/PVDF and its oil rejection coefficient for the membranes. Reprinted/Adapted with permission from ref. [32]. (c) 2008 Elsevier B.V.

\begin{tabular}{cccc}
\hline Membrane & $\begin{array}{c}\text { PVDF } \\
\text { (\%) }\end{array}$ & $\begin{array}{c}\text { SPC } \\
\mathbf{( \% )}\end{array}$ & $\begin{array}{c}\mathbf{R} \\
(\mathbf{\%})\end{array}$ \\
\hline PVDF & 100 & - & 95.46 \\
5-SPC & 95 & 5 & 96.66 \\
10-SPC & 90 & 10 & 96.71 \\
20-SPC & 80 & 20 & 96.63 \\
\hline
\end{tabular}

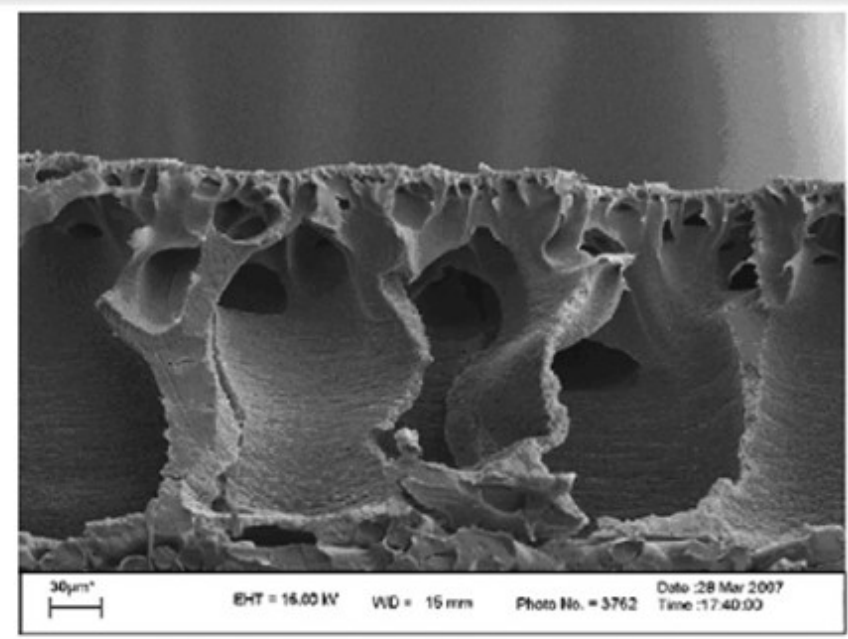

(A) PVDF Magnification $658 \mathrm{X}$

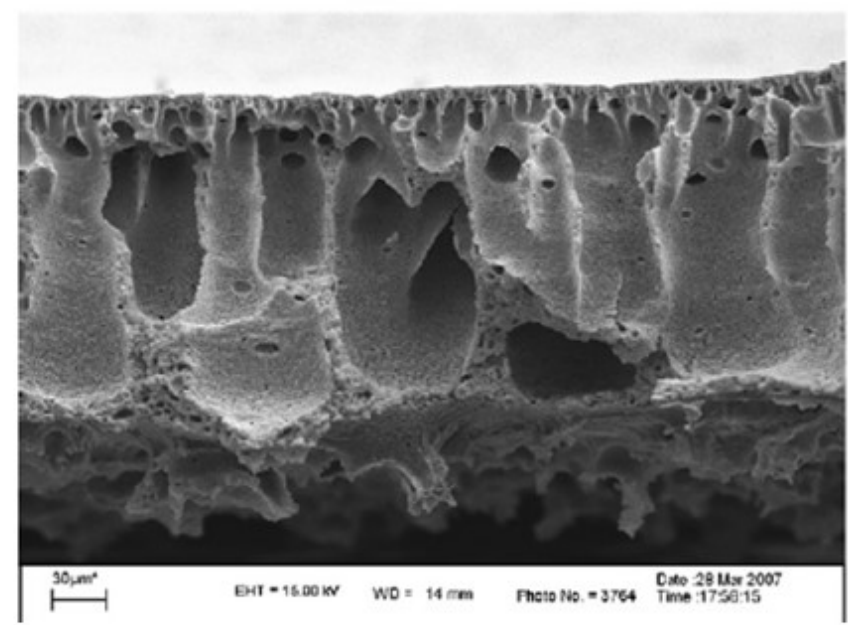

(C) 10SPC Magnification $683 \mathrm{X}$

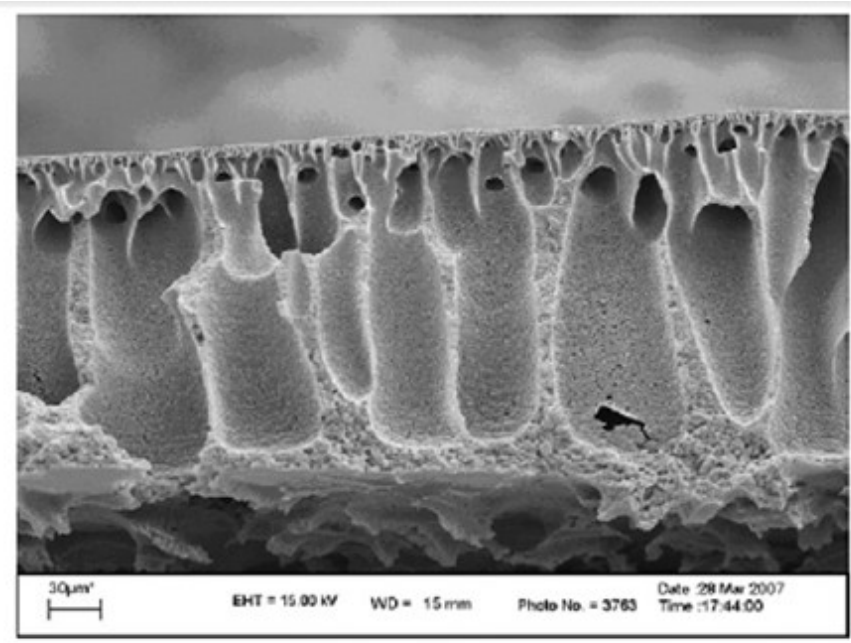

(B) 5SPC Magnification $658 \mathrm{X}$

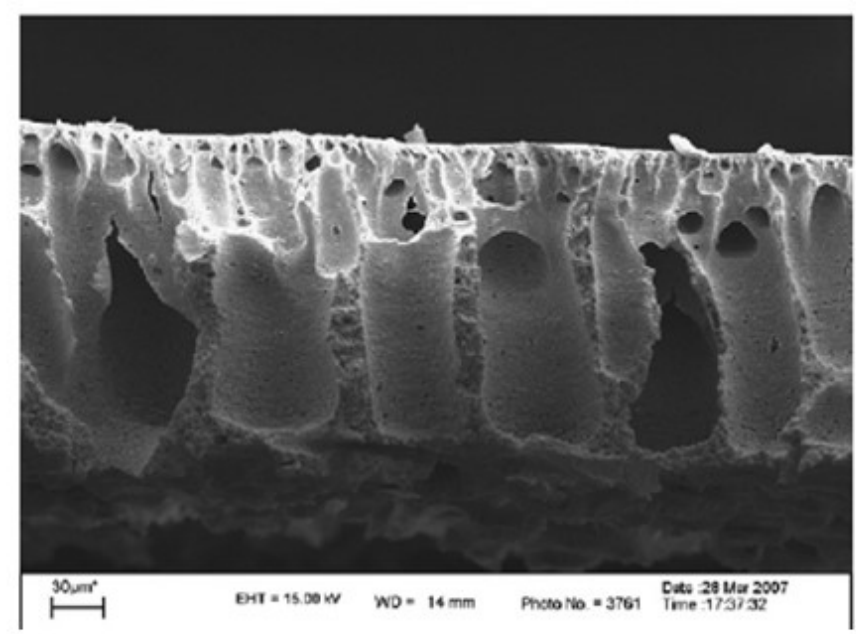

(D) 20SPC Magnification $657 \mathrm{X}$

Figure 1. SEM microphotographs of the Membranes. Reprinted with permission from ref. [32]. (C) 2008 Elsevier B.V.

Besides, polyamide imide-sulfonated poly (ether keton) (PAI-SPEEK) blend hollow fibers for oily wastewater treatment were prepared and investigated extensively by Johari et.al. [34]. Due to an excellent processability for membrane fabrication resulting from the flexible amide groups which can be an attractive amorphous thermoplastic polymer, the porosity was about $79 \%$, the outer surface water contact angle $58^{\circ}$, and the mean pore size $12 \mathrm{~nm}$ and $81 \mathrm{~nm}$ for the membrane prepared by a PAI/SPEEK ratio of 85/15, respectively. The morphological structure and performance of the membrane was tested by FESEM analysis (Figure 2) and UF experiments (Figure 3). From Figure 2, it is found that the membranes have about $0.4 \mathrm{~mm}$ and $0.65 \mathrm{~mm}$ for an inner diameter and an outside 
diameter, respectively. In general, the final membrane morphology is concerning with (thermodynamic and kinetic) effects of the polymer solution. Images show that the larger finger-like cavities were expanded from the outer surface into the membrane matrix by increasing the PAI/SPEEK ratio. Their results showed that the membrane was workable for the UF of oily wastewater treatment and the oil rejection over 95\% [34].
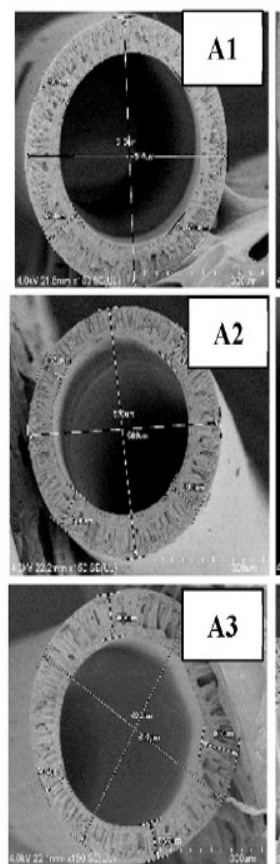
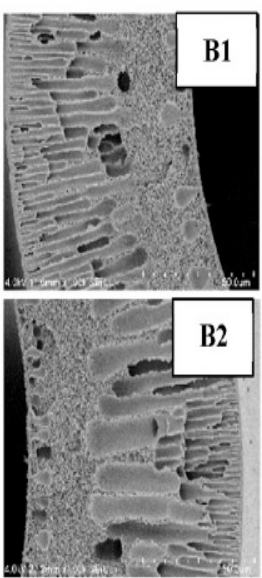

B2
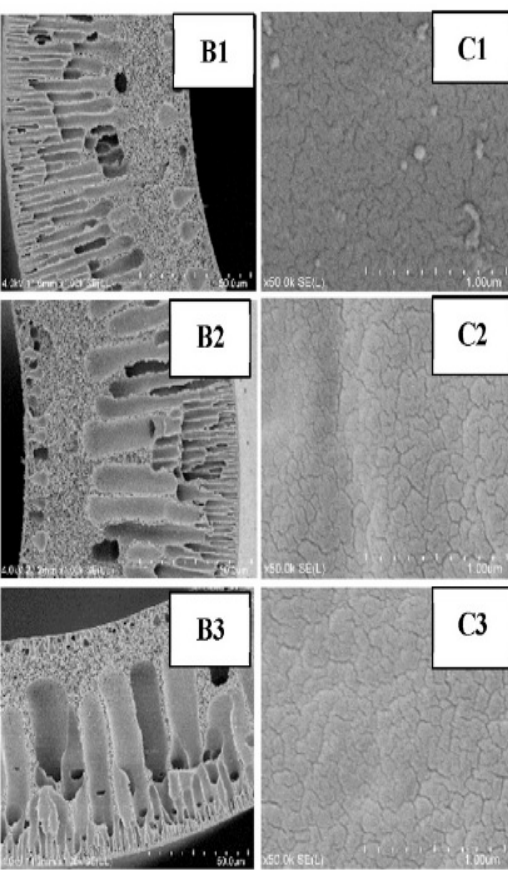

$\mathrm{C} 2$

$\mathrm{C} 3$
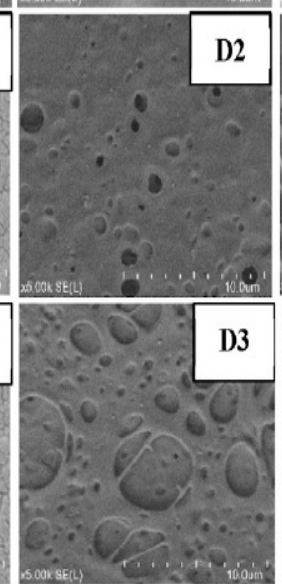
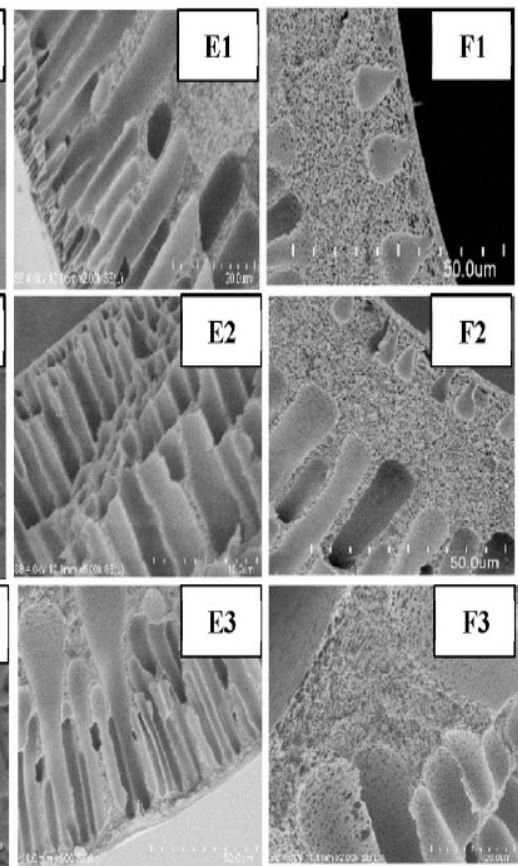

Figure 2. The FESEM images of polyamide imide-sulfonated poly (ether ether keton) (PAI-SPEEK) membranes: (1) 100/0; (2) 95/5; (3) 85/15; (A) cross-section; (B) outer-surface; (C) inner-surface; (D) outer layer; (E) inner layer; (F) inner sponge-like layer. Reprinted with permission from ref. [34]. ㄷ 2020 Elsevier Ltd.

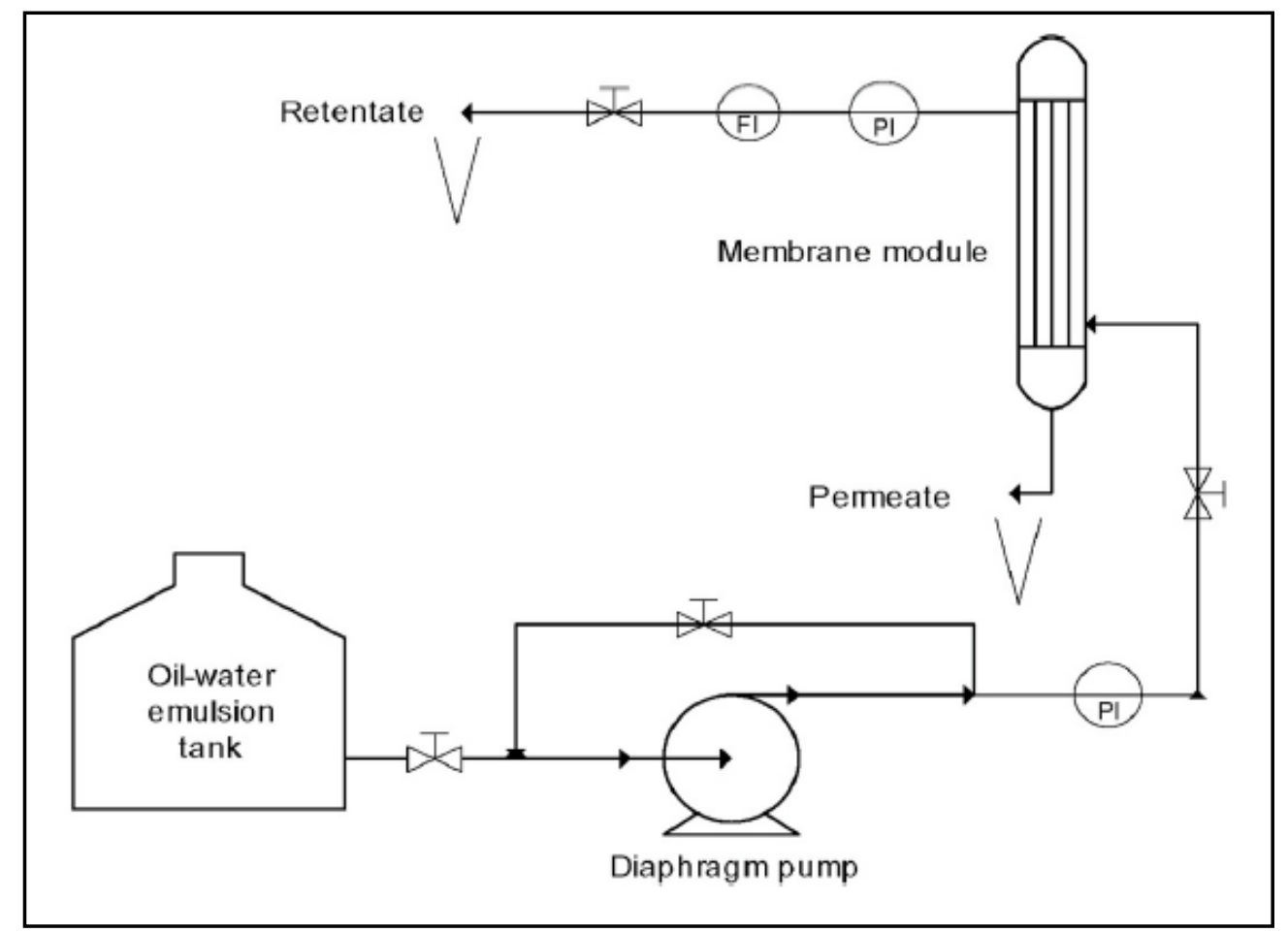

Figure 3. Schematic diagram of the experimental set-up. Reprinted with permission from ref. [34]. (c) 2020 Elsevier Ltd. 
Moreover, similar findings were documented by Chakrabarty et al. who observed a major effect on permeate flux and the removal of oil droplet $(>90 \%)$ by blend membranes composed of PSf, polyethylene glycol (PEG), and polyvinylpyrrolidone (PVP) of various molecular weights. It is noticed that the morphological membranes' properties were clearly changed by the addition of various molecular weights of PVP and PEG [22].

\subsection{Surface Modified-Membranes}

Recently, great interest has been focused on modifying the membranes' surface to enhance membrane performance. A significant criterion for surface modification is improved antifouling and performance which has become a main factor in membrane engineering. Surface modification of the membrane can be produced by either physical (plasma irradiation, Ion beam irradiation, and vapor phase deposition) or chemical techniques (coating, grafting, and acid base treatment) [19]. Zhang et al. used the alkali-induced phase inversion process to prepare PAN UF membranes. The $\mathrm{NaOH}$ is added to the coagulation bath as an additive to induce the wetting property of the PAN membrane through the alkaline-induced phase inversion process, which results in the creation of a rough structure on the membrane surface. The porosity of the PAN membranes prepared in pure water was $64.2 \%$, while the porosity of the PAN membranes prepared in the $\mathrm{NaOH}$ coagulating bath was substantially higher at $(71.7,75.1,79.6) \%$, corresponding to $\mathrm{NaOH}$ concentrations of $(2,5,10) \%$, respectively. The results showed a superior recyclability and antifouling due to its ultra-low oil adherence property and permeation flux of $2270 \mathrm{~L} / \mathrm{m}^{2} \mathrm{~h}$ with an oil removal efficiency of $85 \%$ [28].

Moreover, Rajaeian et al. developed nanocomposite membranes via coating a surface modification porous of $15 \mathrm{wt}$ \% PVDF support with about $2 \mathrm{wt}$ \% of poly (vinylalcohol) (PVA) doped solution containing $\mathrm{TiO}_{2}$ nanoparticles. The compositions of the casting solution of the membrane are shown in Table 3. The results showed that the oil rejection is $91.5 \%$. The best performance was achieved in (M-3) by the embedding of $1 \mathrm{wt} \%$ of carboxylated $\mathrm{TiO}_{2}$ nanoparticles in PVA-coated PVDF membranes as shown in Figure 4, which explains schematically the effect of the carboxylated $\mathrm{TiO}_{2}$ nanoparticles on the structure and performance of the membrane. After carboxylation, $\mathrm{TiO}_{2}$ nanoparticles are more compatible with PVA, so an increase in the number of cross linkages between the PVA hydroxyl moieties and acid groups on the surface of $\mathrm{TiO}_{2}$ is expected. In addition, it clarifies the well-dispersed $\mathrm{TiO}_{2}$ nanoparticles within the PVA (M-3) vs. agglomeration of $\mathrm{TiO}_{2}$ bonded to PVA (M-4), and a lower rejection of solutes was observed [35].

Table 3. Summary of the composition of membrane. Reprinted/Adapted with permission from ref. [35]. (C) 2015 Elsevier B.V.

\begin{tabular}{|c|c|c|c|c|c|}
\hline Membrane & $\begin{array}{l}\text { PVDF } \\
\text { (wt.\%) }\end{array}$ & PVA (wt.\%) & PVP (wt. \%) & $\begin{array}{c}\mathrm{TiO}_{2}-\mathrm{COOH} \\
\text { (wt.\%) }\end{array}$ & $\begin{array}{c}\text { Pure } \mathrm{TiO}_{2} \\
\text { (wt. } \% \text { ) }\end{array}$ \\
\hline PVDF & 15 & - & 2 & - & - \\
\hline M-1 & 15 & 1 & 2 & - & - \\
\hline M-2 & 15 & 1 & 2 & 0.5 & - \\
\hline M-3 & 15 & 1 & 2 & 1 & - \\
\hline M-4 & 15 & 1 & 2 & - & 1 \\
\hline
\end{tabular}

Wandera et al. suggested grafting poly (N-isopropylacrylamide) (PNIPAAm)-block poly (oligo ethylene glycol methacrylate) (PPEGMA) nanolayers from the surface of the membrane to modify the surface of low molecular weight cutoff regenerated cellulose UF membranes, with the aim to prepare antifouling surfaces for produced water treatment. The modification of the membrane enhanced the TOC removal up to $97 \%$ with the reduction in the fouling rate [36]. The same surface modification technique (graft modification) was used by Masuelli et al. for treating oily wastewater by changing the charge of the PVDF membranes. Glycidyl methacrylate (GMA) and ethylene glycol dimethacrylate (EDMA) were utilized as monomers in the grafting polymerization step followed by sulfonation 
using sodium sulfite. The charged PVDF membranes showed about $98 \%$ of oil emulsion rejection [37].

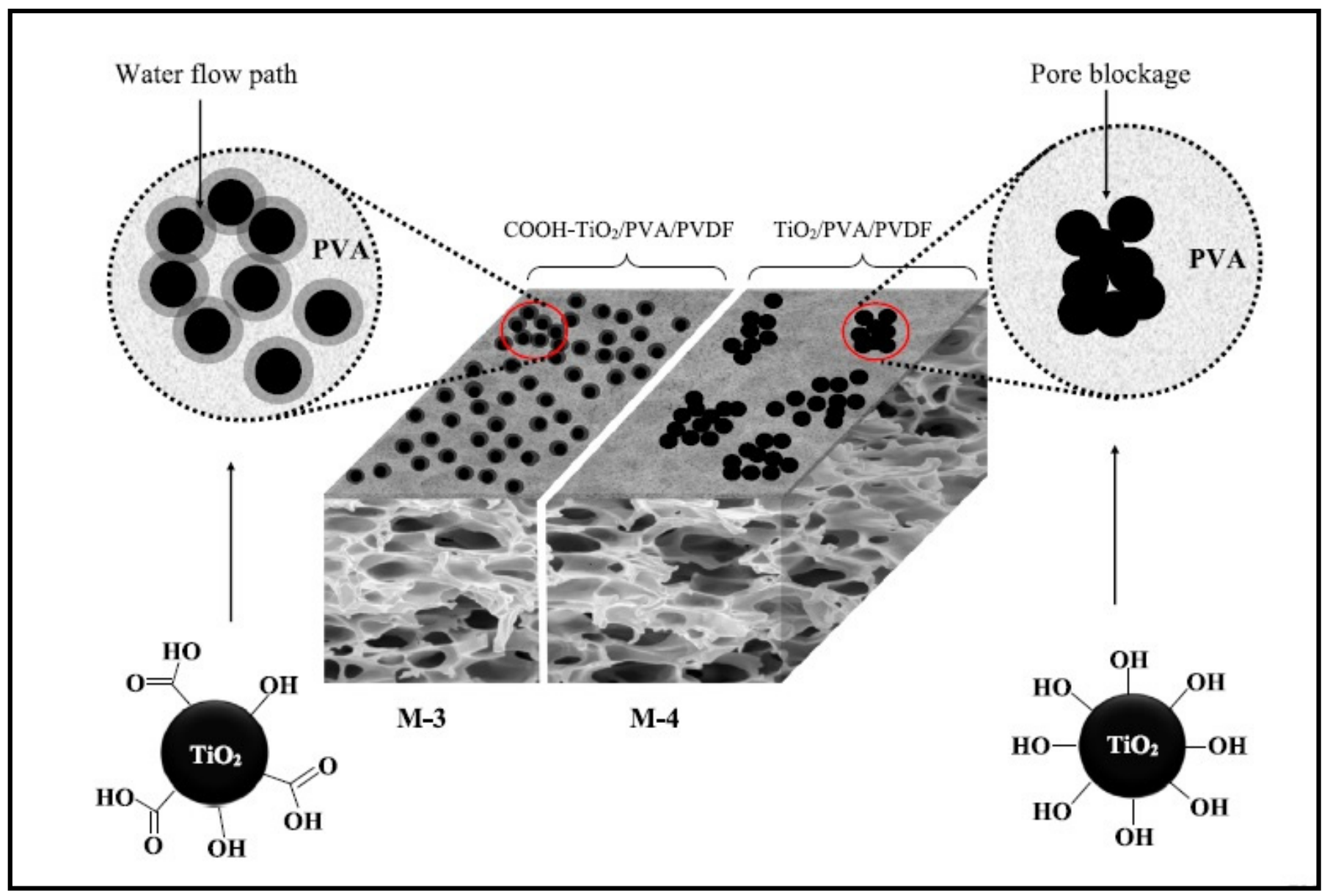

Figure 4. The dispersion of Titanium dioxide $\left(\mathrm{TiO}_{2}\right)$ nanoparticles in membrane (M-3) vs. agglomeration of $\mathrm{TiO}_{2}$ in membrane (M-4). Reprinted with permission from ref. [35]. (C) 2015 Elsevier B.V.

\subsection{Mixed Matrix Membranes (MMM)}

A typical mixed matrix membrane MMM is fabricated by mixing an inorganic particlesuch as silicon dioxide $\left(\mathrm{SiO}_{2}\right)$, carbon nanotubes $(\mathrm{CNTs}), \mathrm{ZnO}$, and $\mathrm{TiO}_{2}$-within a matrix of the polymer. The MMM takes some of the characteristics of inorganic particles, especially their superior performance of separation. The main purpose of this mixing was to incorporate the beneficial properties of the two types of materials, thus enhancing the overall effectiveness. In the current decade, research using MMM has attracted more interest than polymer blending, as it has a greater ability to eliminate particular contaminants and the low fouling phenomenon [41].

The antifouling properties and permeability performance of the membrane were enhanced when adding $\mathrm{SiO}_{2}$ nanoparticles into the blended composition, found by Ahmad et al. through fabricating the PSf MMM. For the modified membrane, the permeate flux (PSf-5) $\left(17.32 \mathrm{~L} / \mathrm{m}^{2} \mathrm{~h}\right)$ showed 16 times an increment in membrane permeability compared to the unmodified membrane (PSf-0) $\left(1.08 \mathrm{~L} / \mathrm{m}^{2} \mathrm{~h}\right)$ (Figure 5) [23]. 


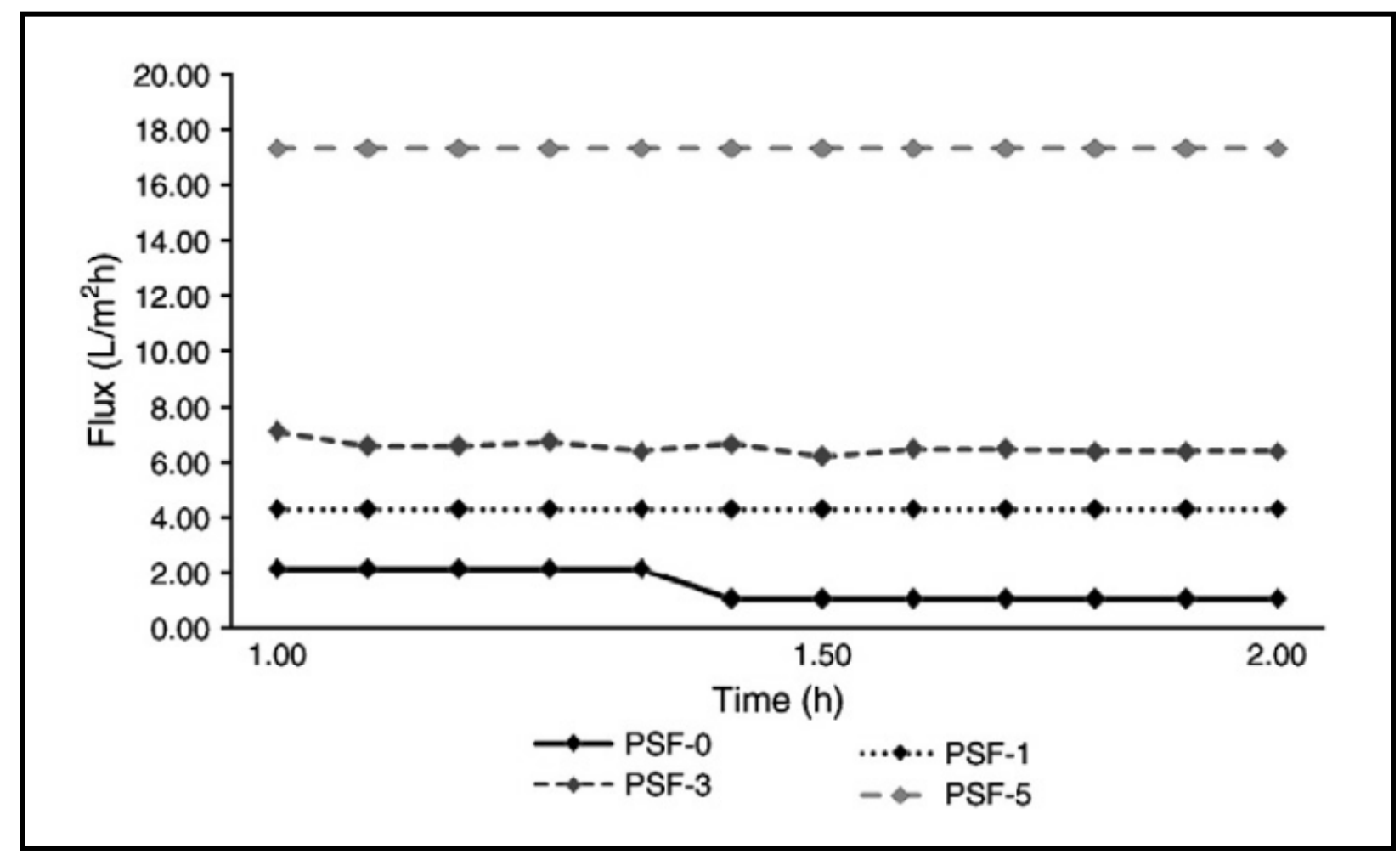

Figure 5. Permeate flux of polysulfone/silicon dioxide (PSf $\left./ \mathrm{SiO}_{2}\right)$ membranes. Reprinted with permission from ref. [23]. (C) 2010 Elsevier B.V.

Besides, $\mathrm{TiO}_{2}$ was also used to increase the membrane hydrophilicity in MMMs. PVDF UF membranes were fabricated by Lithium Chloride monohydrate $\left(\mathrm{LiCl} \cdot \mathrm{H}_{2} \mathrm{O}\right)$ and $\mathrm{TiO}_{2}$ nanoparticles by Yuliwati and Ismail for treating oily wastewater using MMM. At (1.95 wt.\%) $\mathrm{TiO}_{2}$, the membrane presented a maximum flux $\left(82.5 \mathrm{~L} / \mathrm{m}^{2} \mathrm{~h}\right)$ and an oil removal rejection of $(98.83 \%)$, respectively [38]. Similar work was also studied by Ong et al. where they discovered that at $(2 \mathrm{wt} . \%) \mathrm{TiO}_{2}$, the $\mathrm{PVDF}^{-\mathrm{TiO}_{2}}$ membrane had the highest flux [39].

Moreover, Ong et al. studied hollow fiber MMM at various concentrations of $\mathrm{TiO}_{2}$ in the PVDF and found that with the addition of PVP, the membrane showed that the added ( $2 \mathrm{wt} . \%) \mathrm{TiO}_{2}$ concentration in the PVDF membrane played an important role in improving membrane structure by enhancing membrane hydrophilicity, pore size, and surface roughness at a $(2 \mathrm{wt} . \%) \mathrm{TiO}_{2}$ concentration. The presence of hydrophilic PVP with $\mathrm{TiO}_{2}$ nanoparticles had substantially improved membrane porosity. The porosity was found to be $(84.10-88.60 \%)$, the water contact angle was $(68.40-75.70)^{\circ}$, and the pore size was (94.30-104.40) nm. the $\mathrm{PVDF}^{-\mathrm{TiO}_{2}}$ membrane had the water flux $70.48 \mathrm{~L} / \mathrm{m}^{2} \mathrm{~h}$ and oil rejection 99.7\% [40]. In addition, $\mathrm{Yi}$ et al. used $\mathrm{TiO}_{2} / \mathrm{Al}_{2} \mathrm{O}_{3}$ with PVDF MMM for oil/water emulsion separation. The results showed a better antifouling pattern when using modified PVDF membranes compared to the pristine PVDF membrane under the same conditions [41].

\section{Membranes Structure and Performance}

Membrane performance depends on its structure that is controlled through membrane synthesis methods, polymer (type and composition), and additives (type and composition). To gain the desirable performance of the membrane, many researchers investigated the effect of (i) membrane synthesis techniques, (ii) polymer selection and alterations methods, (iii) additives type and their concentration, etc. on the morphology of the membrane and thus on membrane performance. 


\subsection{Membranes Synthesis Techniques}

Various synthesis techniques were employed to fabricate superhydrophilic surfaces of the membranes. The choice of the membrane synthesis technique is so important to improve the membrane performance with a view to modify the characteristics of the surface (i.e., roughness, hydrophilicity, biocompatibility, and functionality) to obtain the desirable membrane properties and morphologies. The most common techniques are phase inversion [8,27,28], interfacial polymerization [42,43], spray-assisted layer-by-layer [44,45], and polymer grafting $[36,46]$. Table 4 summarizes the most common synthesis technique of membranes.

Table 4. Examples of research on the most common synthesis technique of membranes.

\begin{tabular}{|c|c|c|c|c|}
\hline Membrane Type & Synthesis Technique & Water Flux (LMH) & Removal Efficiency \% & Ref. \\
\hline PVC/MWCNT-g-GO & phase inversion & 254.00 & COD rejection $60.00-88.90$ & [9] \\
\hline PNIPAAm)-block (PPEGMA) & polymer grafting & - & Rejection $>97.00$ & [36] \\
\hline $\mathrm{PES} / \mathrm{GO}-\mathrm{SiO}_{2} \mathrm{MMM}$ & phase inversion & - & Oil rejection 38.00 & [20] \\
\hline PVDF/GO@SiO 2 /PVP & phase inversion & 1232.00 & Rejection rate 78.50 & {$[47]$} \\
\hline PMMA-MWCNTs composites & $\begin{array}{c}\text { interfacial } \\
\text { polymerization }\end{array}$ & - & $\mathrm{Na}_{2} \mathrm{SO}_{4}$ rejection $>99.00$ & [42] \\
\hline Thin-film composite PA/PVDF & $\begin{array}{c}\text { interfacial } \\
\text { polymerization }\end{array}$ & 1654.98 & - & [43] \\
\hline CuNP-functionalized membrane & $\begin{array}{l}\text { Spray-assisted } \\
\text { layer-by-layer }\end{array}$ & - & - & [44] \\
\hline PES/F-MWCNTs membrane & $\begin{array}{l}\text { Spray-assisted } \\
\text { layer-by-layer }\end{array}$ & - & - & [45] \\
\hline $\begin{array}{l}\text { A-MWCNTs/PVDF } \\
\text { membrane }\end{array}$ & polymer grafting & 900.00 & Oil rejection $>99.00$ & [46] \\
\hline
\end{tabular}

\subsubsection{Phase Inversion Technique}

In the phase inversion technique or method, a de-mixing process in which at first a polymer solution with a homogeneous form is converted from a liquid phase to a solid phase in a controlled mode. This technique is commonly utilized to prepare polymeric membranes with a porous structure. In the phase inversion method, any polymer-if it is soluble in a solvent or mixture of solvents - can be utilized to fabricate a membrane. The performance and morphology of the membrane can be improved by controlling the polymer-solvent interaction through a choice of a suitable solvent $[48,49]$.

The phase inversion technique is commonly used to prepare asymmetric polymeric membranes. Various methods are utilized to precipitate polymer solutions in the phase inversion technique, such as immersion precipitation or non-solvent induced phase inversion (NIPS), evaporation induced phase inversion (EIPS), vapor induced phase inversion (VIPS), and thermally induced phase inversion (TIPS). Due to easier preparation of NIPS, it is considered to be the most widely used technique among phase inversion techniques for preparation of polymeric membranes for the desired morphology $[8,11]$.

Alkindy et al. fabricated a PES-based $\mathrm{GO}-\mathrm{SiO}_{2}$ membrane for oily wastewater treatment by the phase inversion technique, as shown in Figure 6. PES/GO-SiO membrane $^{2}$ was prepared using a loading concentration of $(1.0 \mathrm{wt} . \%)$ of the nanoparticle to the polymer. The nanoparticle was dispersed in DMAc and ultrasonicated in a water bath for $30 \mathrm{~min}$. PVP (4 wt.\%) was dissolved in the solution followed by the addition of PES (16 wt.\%) and stirred for $24 \mathrm{~h}$ at $60^{\circ} \mathrm{C}$. The dope solution was set aside for $24 \mathrm{~h}$ to remove trapped air bubbles (i.e., membrane degassing). The solution was subsequently cast on a polyester membrane support on clean glass at a thickness of $200 \mu \mathrm{m}$. The glass plate was immersed horizontally into deionized (DI) water at a temperature of $25^{\circ} \mathrm{C}$ for $24 \mathrm{~h}$. Finally, the 
membranes were washed with DI water and stored for use. The membrane showed the highest water flux (2561 LMH) and a 38\% increase in oil removal efficiency in comparison to a PES membrane [20].

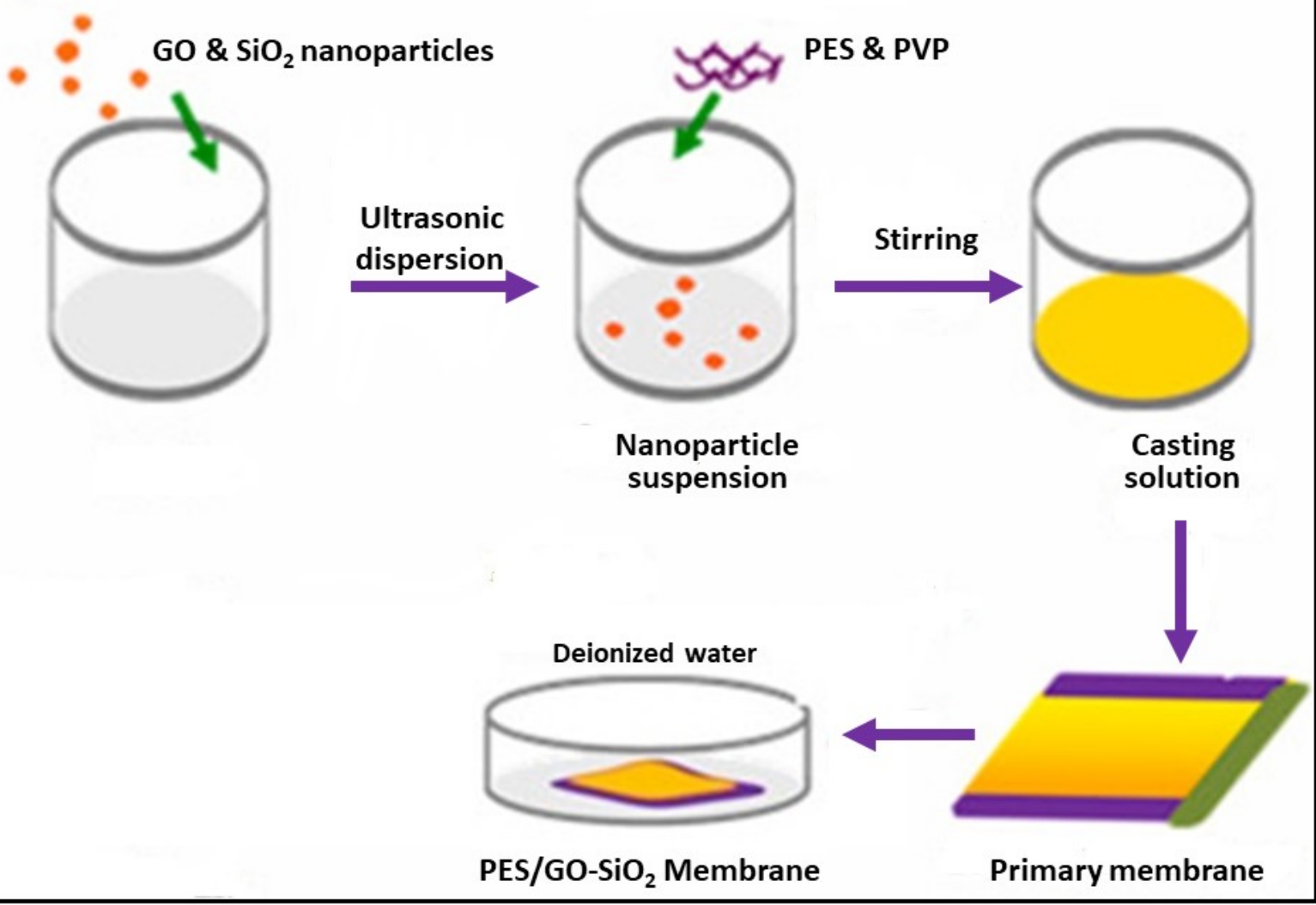

Figure 6. Schematic diagram of preparing polyethersulfone/graphene oxide-silicon dioxide $\left(\mathrm{PES} / \mathrm{GO}^{-S i O} \mathrm{O}_{2}\right) \mathrm{membrane}$ using phase inversion technique.

Zhu et al. prepared novel membranes by introducing nanohybrid particles $\left(\mathrm{GO} / \mathrm{SiO}_{2}\right)$ and polyvinylpyrrolidone (PVP) into PVDF polymer solution through the phase inversion technique. $\mathrm{GO}$ and $\mathrm{SiO}_{2}$ nanoparticles were sonicated for $1 \mathrm{~h}$ after being applied to $(0.3$ wt.\%) DMAC solvent. Polyvinyl pyrrolidone (PVP) powder and PVDF powder were added successively and stirred until the PVDF material had fully dissolved. The homogeneous polymer solution was permitted to fix at $60{ }^{\circ} \mathrm{C}$ for $12 \mathrm{~h}$ for deaeration. After extracting the bubbles, the polymer solution was cast onto a glass board. After that, the glass board was immersed horizontally in pure water at $20^{\circ} \mathrm{C}$ for $24 \mathrm{~h}$ to extract the solvent by the coagulation bath. At the end, the membrane was washed frequently with DI water, and kept in it at $4{ }^{\circ} \mathrm{C}$. Figure 7 shows the SEM cross sections and the AFM image of the nanohybrid membrane. The SEM cross section shows that the membrane has a composite porous structure with a skin layer and a characteristic asymmetric finger-like porous sublayer, and the AFM image shows many serrated and conical protrusions seemingly on the surface of the PVDF/GO@ $\mathrm{SiO}_{2}$ /PVP membrane, due to the difference in the roughness of the membrane which contributed to the nucleation and growth of the polymer produced by the addition of nanofillers [47]. 

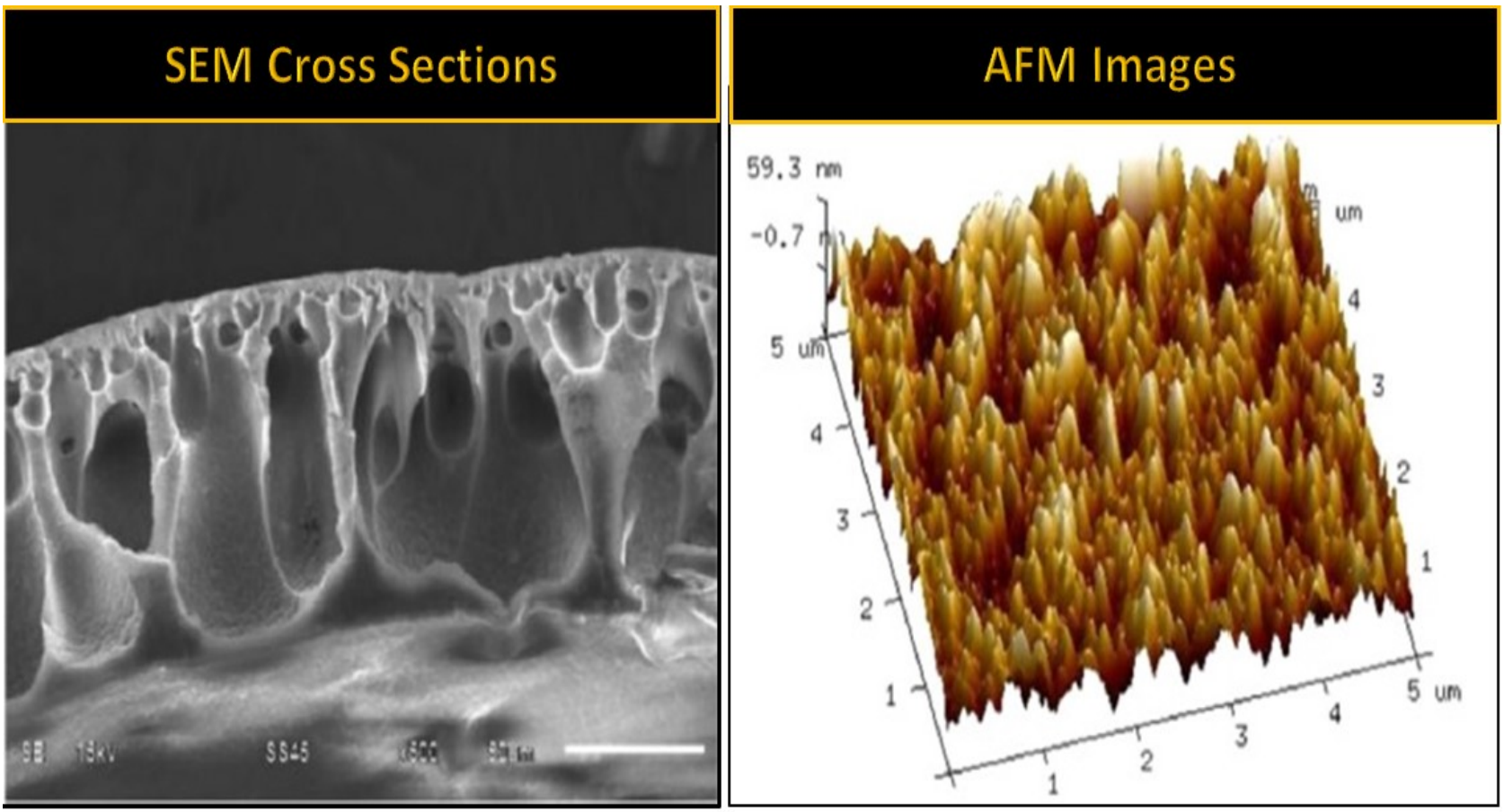

Figure 7. SEM cross sections and AFM images of the nanohybrid membrane. Reprinted with permission from ref. [47]. (c) 2016 Elsevier B.V.

Jalal et al. prepared a (PVC/MWCNT-g-GO) membrane by using the phase inversion method for the treatment of Al-Dura Refinery (in Baghdad, Iraq) wastewater. The dope solution was prepared by dissolving (15 wt.\%) PVC in the ( $85 \mathrm{wt} . \%)$ DMAc solvent in a glass flask at a room temperature of $23 \pm 1{ }^{\circ} \mathrm{C}$. Then, the solution was left for $24 \mathrm{~h}$ to remove the bubbles completely. Different amounts of MWCNT-g-GO $(0.0599,0.119$, and $0.219 \mathrm{wt.} \%$ ) were separately added to the PVC solution. The composite PVC membranes were put in DI water at room temperature for precipitation. Then, it was transferred and stored in glycerol solution ( $40 \mathrm{wt} . \%$ ) for $48 \mathrm{~h}$ to maintain the membrane structure from collapse. The water permeate flux was $254 \mathrm{~L} / \mathrm{m}^{2} \mathrm{~h}$ for $0.119 \mathrm{wt} . \%$ of MWCNT-g-GO; the membrane promoted increases in the permeation flux $66 \%$ higher than using the neat PVC $\left(153 \mathrm{~L} / \mathrm{m}^{2} \mathrm{~h}\right.$ ). Due to the presence of a MWCNT-g-GO hybrid in the membrane, which changes the organization of the PVC chain packing to become disordered, resulting in better structural features, the mean pore size was (194 and 259) $\mathrm{nm}$ and the water contact angle $\left(34^{\circ}\right.$ and $\left.13.9^{\circ}\right)$ for $(0.0599$ and 0.119$)$ wt.\% MWCNTS-g-GO, respectively, in the PVC solution [9].

\subsubsection{Interfacial Polymerization Technique}

By interfacial polymerization, Shen et al. fabricated polyamide thin-film nanocomposite (PA-TFN) membranes functionalized MWNTs grafted by poly (methyl methacrylate) (PMMA). The PA-TFN formed in a piperazine (PIP) solution by immersing PSf substrates. Then, the PMMA-MWCNTs and trimesoyl chloride (TMC) solution in toluene were poured at the PIP-soaked substrate. At ambient pressure, the PA-TFN membrane was put in an oven at $80^{\circ} \mathrm{C}$ in air. Then, the TFN membranes were kept in DI water and stored at $20{ }^{\circ} \mathrm{C}$ before use, resulting in the pure water flux $\left(\sim 1.94 \times 10^{-3} \mathrm{~cm}^{3} / \mathrm{cm}^{2} \cdot \mathrm{s}\right)$ through PMMA-MWCNTs (0.67 wt.\%)/PA (PIP/TMC) membrane [42].

Marquez et al. prepared thin-film composite PA membranes by cosolvent-assisted interfacial polymerization on the external surface of PVDF fiber. Table 5 summarizes the interfacial polymerization conditions. Firstly, the PVDF fiber was kept in an aqueous solution containing acetone of varying concentrations and $2 \mathrm{wt} . \%$ monomer $\mathrm{m}$-phenylenediamine (MPD) for $5 \mathrm{~min}$. The wet PVDF was contacted to an organic phase consisting of $0.5 \mathrm{wt} . \%$ 
TMC/toluene solution for $2 \mathrm{~min}$, and then a PA layer formed immediately. Finally, the membrane was dried by air for $10 \mathrm{~min}$ to obtain extra polymerization; the ATR-FTIR spectra of PVDF and thin film composite PA/PVDF fiber are shown in Figure 8. The water concentration and the permeation flux were $99.88 \mathrm{wt} . \%$ and $1654.98 \mathrm{~L} / \mathrm{m}^{2} \mathrm{~h}$, respectively [43].

Table 5. Summary of interfacial polymerization conditions.

\begin{tabular}{ccccc}
\hline Monomer Solution & $\begin{array}{c}\text { Monomer } \\
\text { Concentration }\end{array}$ & $\begin{array}{c}\text { Immersion } \\
\text { Time }\end{array}$ & Cosolvent & $\begin{array}{c}\text { Cosolvent } \\
\text { Concentration }\end{array}$ \\
\hline Aqueous-phase MPD & $2.00 \mathrm{wt} . \%$ & 5 & Acetone & $0,25,50,75,100$ \\
\hline Organic-phase TMC & $0.50 \mathrm{wt} . \%$ & 2 & None & N/A \\
\hline
\end{tabular}

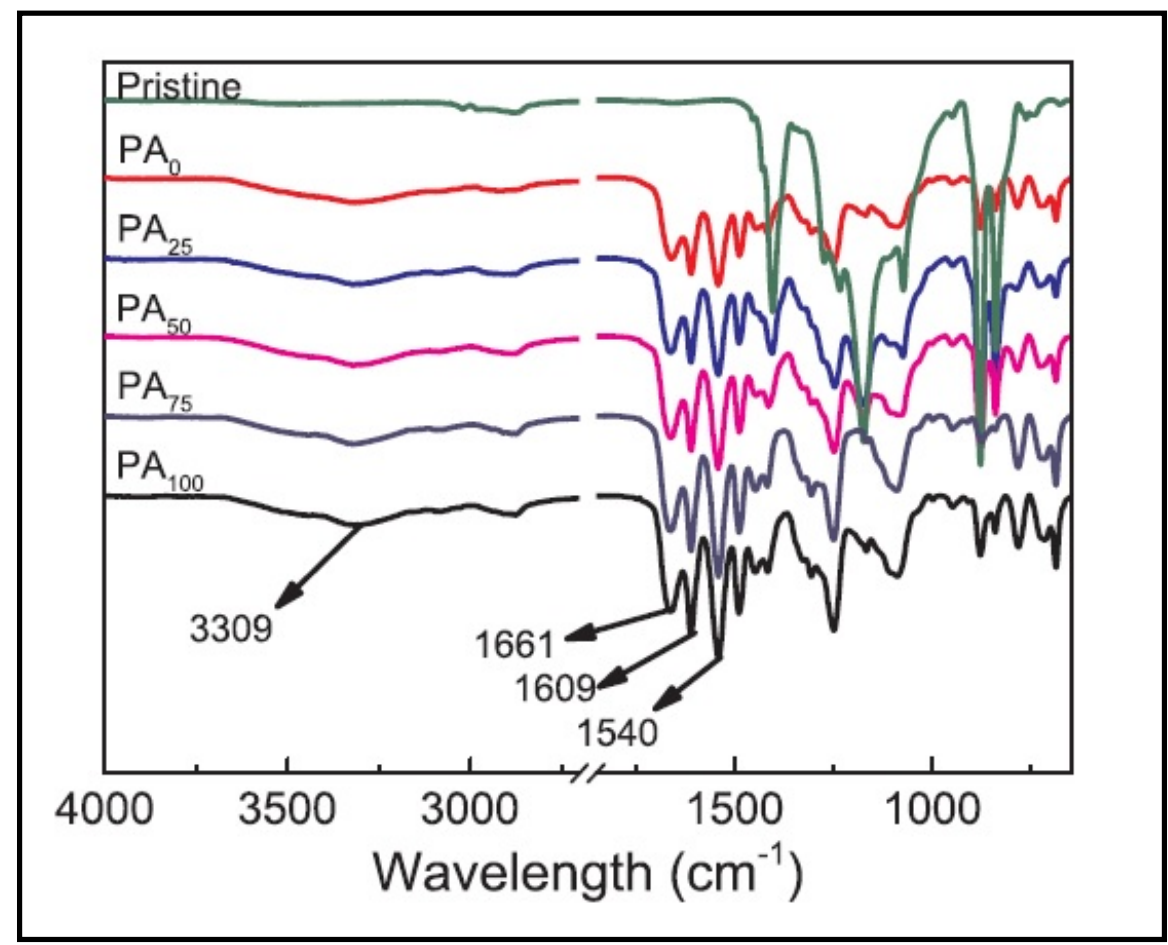

Figure 8. ATR-FTIR spectra of polyvinylidene fluoride (PVDF) and polyamide membranes by using different concentrations of acetone in aqueous phase through interfacial polymerization. Reprinted with permission from ref. [43]. (c) 2018 Elsevier B.V.

\subsubsection{Spray-Assisted Layer-by-Layer Technique}

Ma et al. established a highly efficient spray-and spin-assisted layer-by-layer (SSLbL) method for functionalizing thin film composite TFC-PA membranes with controllable copper nanoparticles CuNPs for biofouling power. A membrane coupon was adhered to a polycarbonate plate and rotated at $2000 \mathrm{rpm}$ while being sprayed coated ( $2.1 \mathrm{bar})$. The membrane was swilled with DI water between each layer deposition and dried in the air for $10 \mathrm{~s}$ (with only spinning). This process completed one step of LbL deposition, resulting in a single polyethyleneimine-CuNPs/poly (acrylic) acid (PEI-CuNPs/PAA) bilayer. Multilayer coating showed a minor impact on the water permeation flux (13.3\% reduction). CuNPs could enhance the anti-biofouling property of a PA membrane and efficiently inhibit the permeate flux reduction caused by bacterial deposition on the membrane surface [44].

Liu et al. used a spray-assisted layer-by-layer technique to fabricate the PES/FMWCNTs membrane. The F-MWCNTs were added to ethanol aqueous solution and ultrasonicated; after that, it was mixed with MWCNTs solution to form a homogeneous poly (sodium 4-styrenesulfonate) PSS solution with MWCNTs content with the aid of 
another ultrasonication. The poly (diallyl-dimethylammonium chloride) (PDDA) polymer was spiked into DI water to prepare PDDA aqueous solution. The PES substrates were soaked in DI water at $25^{\circ} \mathrm{C}$ for $24 \mathrm{~h}$ for removing the wetting agent of the membrane. The pure water flux of the bare PES membrane was reduced with more bilayer deposition of polyelectrolyte/MWCNTs [45].

\subsubsection{Polymer Grafting Technique}

Wandera et al. used grafting PNIPAAm-b-PPEGMA nanolayers by surface-initiated atom transfer radical polymerization (ATRP) to modify the surface of low molecular weight cutoff regenerated cellulose UF membranes, with the aim to fabricate antifouling surfaces for produced water treatment. Figure 9 shows how to use surface-initiated ATRP to modify a regenerated cellulose UF membrane with PNIPAAm-b-PPEGMA. After contacting ATRP initiator molecules with the membrane, surface-initiated ATRP was used to graft PNIPAAm chains from the initiator groups. Then, by re-starting PNIPAAm chains, PPEGMA (as the second polymer block) was grafted. The rejection was up to $97 \%$, and the fouling rate decreased [36].
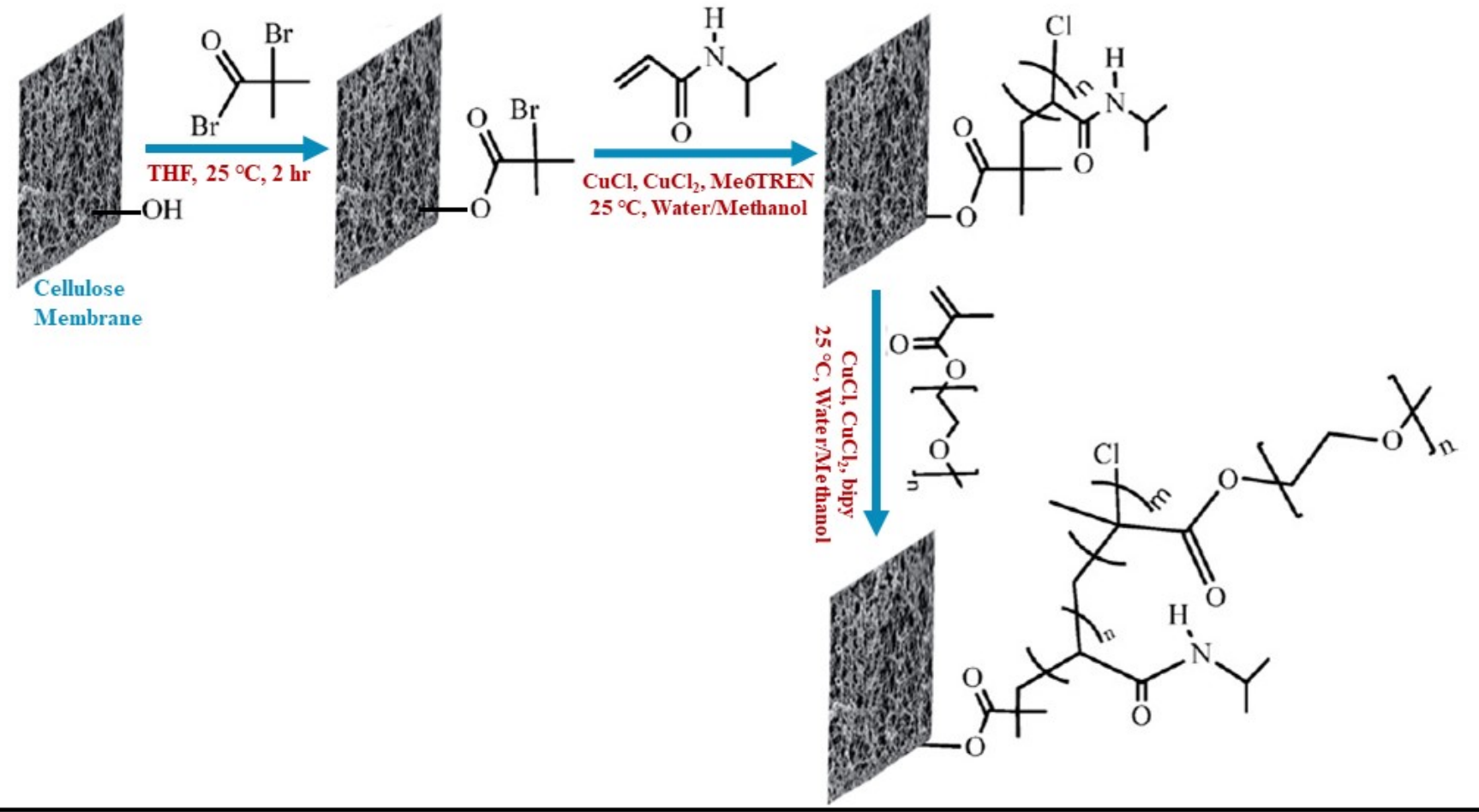

Figure 9. Schematic diagram of surface-initiated ATRP of poly (N-isopropylacrylamide) (PNIPAAm)-block-poly (oligoethylene glycol methacrylate) (PPEGMA) from cellulose Reprinted with permission from ref. [36]. (c) 2011 Elsevier B.V.

Yang et al. prepared DA/A-MWCNTs-treated PVDF membranes. First, they functionalized (MWCNTs) by grafting 3-aminopropyltriethoxysilane (APTES) and then decorated onto the PVDF membrane surface directly by dopamine copolymerizes. The membrane had high flux $\left(900 \mathrm{~L} / \mathrm{m}^{2} \mathrm{~h}\right)$ and excellent efficiency ultra-high oil rejection $(>99 \%)$. A schematic diagram of the preparation of the DA/APTES-MWCNTs decorated superhydrophilic PVDF membrane is shown in Figure 10 [46]. 


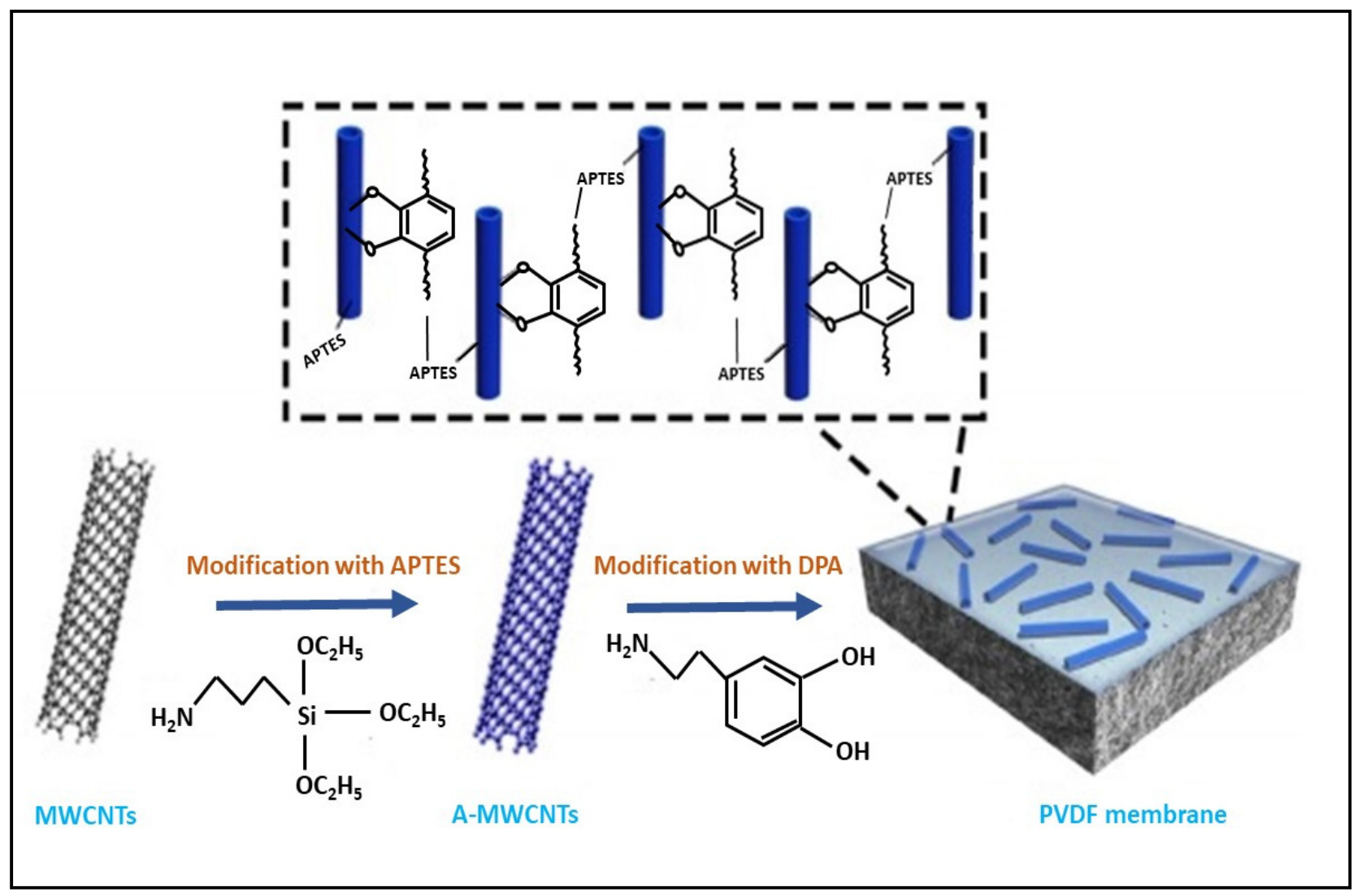

Figure 10. Schematic diagram of fabrication dopamine/3-aminopropyltriethoxysilane-multiwall carbon nanotubes (DA/APTES-MWCNTs) decorated superhydrophilic polyvinylidene fluoride PVDF membrane. Reprinted with permission from ref. [46]. (C) 2019 Springer Science+Business Media, LLC, part of Springer Nature.

\subsection{Polymer Selection and Alterations Methods}

Membrane hydrophilicity, as well as chemical, mechanical, and thermal stability of the membrane, are influenced by the polymer selection. During membrane synthesis, it plays a vital role because solvent selection depends on the polymer solubility in the solvent [8].

Various approaches, such as physical blending, chemical grafting, and surface modifications, were used in several studies to enhance membrane performance [50]. The physical blending polymer is one of these methods that has gotten a lot of attention because of the materials' comfortable operations, mild conditions, and good performances [38,51]. The effect of the polymer alterations methods on the membrane performance is described in Section 2 in detail.

\subsection{Type of the Nanoparticle (NPs) Additives}

Development of antifouling membranes is an intensive research area in membrane engineering. Using nanoparticles in fabricating membranes allows the ability to produce the desired structure of membranes which enhances the property of the membrane materials, and a high degree of control of the membrane fouling and permeability as well as the permeability quality [52]. Modifying the hydrophilic group on the membrane surface and creating micro-nanostructures on the surface of the membrane to increase roughness improved the membrane's hydrophilicity [53].

Nanoparticles (NPs) are classified into many groups based on their size, shape, and chemical and physical properties. Some of them are polymeric nanoparticles, carbonbased NPs, semiconductor NPs, ceramic NPs, lipid-based NPs, and metal NPs [54]. The nanoparticles that have been embedded in the matrix of the membrane are MWCNTs, halloysite nanotubes (HNTs), $\mathrm{TiO}_{2}, \mathrm{MgO}, \mathrm{SiO}_{2}, \mathrm{GO}, \mathrm{ZnO}$, etc. [4]. Table 6 summarized the type of NPs and effect on the membrane performance. 
Table 6. Examples of research on the type of nanoparticles (NPs) and effect on the membrane performance.

\begin{tabular}{|c|c|c|c|c|c|c|c|c|c|c|}
\hline \multirow[b]{2}{*}{ Polymer } & \multirow[b]{2}{*}{ Method } & \multirow[b]{2}{*}{ Additive Type } & \multirow[b]{2}{*}{ Additive Conc. } & \multicolumn{5}{|c|}{ Properties } & \multirow{2}{*}{$\begin{array}{c}\text { Performance } \\
\text { Water Flux, } \\
\text { LMH }\end{array}$} & \multirow[t]{2}{*}{ Ref. } \\
\hline & & & & $\begin{array}{l}\text { Thickness, } \\
\mu \mathrm{m}\end{array}$ & $\begin{array}{l}\text { Contact } \\
\text { Angle }\end{array}$ & Pore Size, nm & Porosity \% & Rejection & & \\
\hline PVC/MWCNT-g-GO & Phase inversion & MWCNT-g-GO & $\begin{array}{l}0.06,0.12 \text {, and } \\
0.22 \text { wt. } \%\end{array}$ & - & $13.9-34$ & $194-259$ & 81.4 & $\begin{array}{c}\text { COD rejection } \\
88.9 \%\end{array}$ & $\begin{array}{c}254.00 \text { at } 0.12 \\
\text { wt. } \%\end{array}$ & [9] \\
\hline PVDF/GO@SiO 2 /PVP & Immersion precipitation & $\mathrm{GO} @ \mathrm{SiO}_{2}$ & 0.30 wt. $\%$ & 100.00 & - & - & - & - & 1.23 & [47] \\
\hline PVDF MF membrane & - & $\mathrm{GO} / \mathrm{TiO}_{2}$ & GO $20.00 \mu \mathrm{g}$ & - & $62.00-162.00$ & - & - & $\begin{array}{l}\text { Oil rejection } \\
\quad 70.2 \%\end{array}$ & 531.00 & [53] \\
\hline $\begin{array}{c}\text { PES/PDA/N-MWCNTs } \\
\text { membranes }\end{array}$ & Coating & N-MWCNTs & $\begin{array}{l}0.01 \text { and } 0.05 \\
\text { wt. } \%\end{array}$ & - & $30.20-38.70$ & 12.77 & - & $\begin{array}{l}\text { Oil rejection } \\
\quad 99 \%\end{array}$ & 90.85 & [21] \\
\hline PVDF/MWCNTs & - & MWCNTs & & 200.00 & & $20.00-60.00$ & $54.02-89.36$ & - & 700.00 & {$[55]$} \\
\hline $\begin{array}{l}\text { PSf hollow fiber } \\
\text { membranes }\end{array}$ & Embedded & $\mathrm{CNTs} / \mathrm{GO}$ & $1.00 \mathrm{wt} . \%$ & - & - & - & - & $\begin{array}{l}\text { Oil rejection } \\
98.7 \pm 1.2 \%\end{array}$ & $487.90 \pm 25.40$ & [25] \\
\hline PPSU/ZnO-NPs & Phase inversion & $\mathrm{ZnO}-\mathrm{NPs}$ & 0.03 wt. $\%$ & - & - & - & - & - & $76.00-107.00$ & [56] \\
\hline
\end{tabular}




\subsubsection{Carbon-Based Nanoparticles}

CNTs are one of the most common types of carbon-based NPs. CNTs have an elongated, tubular structure and can be single named as single-walled (SWNTs), double named as double-walled (DWNTs), or many walls named as multi-walled carbon nanotubes (MWCNTs) [54]. MWCNTs were one of the strong additives with remarkable properties such as high thermal conductivity, individual mechanical property, and high specific surface area. The addition of functionalized MWCNTs allows high permeation flux due to reducing the formation boundary layers at the membrane surface and raising the membrane surface roughness [9].

As an example of the research works found in the literature that used CNTs as embedded material, Saadati and Pakizeh prepared a new PSf/pebax/F-MWCNTs nanocomposite membrane for oil/water emulsion. For enhancing the membrane characteristics, $(0.5,1$, and 2) wt.\% of F-MWCNT was applied to pebax solution, achieving the higher permeate flux at (0.5 wt.\%) F-MWCNTs and the best oil rejection at (2 wt.\%) F-MWCNTs [24]. Zarghami et al. developed a novel, fast, and facile post-functionalization of PES/PDA/N-MWCNTs membranes by utilizing amino-functionalized MWCNTs (N-MWCNTs) nanoparticle; FESEM images are shown in Figure 11. The developed membranes present high oil rejection $(>99 \%)$ and flux $(\sim 1086 \%)$ compared to the undeveloped PES membrane. Moreover, evaluation of the modified membrane in cross-flow filtration produced its antifouling properties through the long-term application (16 r) [21]. Moreover, MWCNTs were used by Jalal et al. to fabricate (PVC/MWCNT-g-GO) membranes for treating refinery wastewater. The permeation flux of (0.119 wt.\%) MWCNT-g-GO was $254 \mathrm{~L} / \mathrm{m}^{2} \mathrm{~h}$, and the COD rejection increased dramatically from $(60 \%)$ neat PVC to $(88.9 \%)$ for both membranes made from PVC plus (0.119 or 0.219 ) wt.\% of MWCNT-g-GO [36]. In addition, the PVDF/MWCNTs nanocomposite membrane system was developed by Moslehyani et al. The experiment was conducted by comparing neat PVDF, original PVDF/MWCNTs, and oxidized PVDF/MWCNTs (Figure 12) with water fluxes of $(50,520$, and 700$) \mathrm{L} / \mathrm{m}^{2} \mathrm{~h}$, respectively, in one hour [55].

Moreover, a nanohybrid including carboxylate CNTs/GO nanosheets was incorporated in PSf hollow fibers by Modi and Bellare to enhance the physicochemical characteristics, hydrophilicity, thermal and mechanical stability, and separation performance. The CNTs and GO nanosheets significantly affect high-water flux $\left(487.9 \pm 25.4 \mathrm{~mL} / \mathrm{m}^{2} / \mathrm{h} / \mathrm{mmHg}\right)$, greater antifouling property (flux recovery $\sim 90.5 \%$ ), and oil rejection $(98.7 \pm 1.2 \%$ ) [25].

\subsubsection{Semiconductor Nanoparticles}

Semiconductor materials have properties that are similar to both metals and nonmetals, so a wide range of semiconductor NPs are extremely effective in water applications. Some examples of semiconductor nanoparticles are $\mathrm{ZnO}, \mathrm{ZnS}, \mathrm{GaN}, \mathrm{GaP}, \mathrm{CdS}$, and CdSe [54].

One of the popular low-cost semiconductor NPs is ZnO; this NPs was used by Alsalhy et al. to prepare polyphenylsulfone PPSU/ZnO-NPs membranes, and they found that the hydrophilicity, mean roughness, and mean pore size were improved by increasing the $\mathrm{ZnO}-\mathrm{NPs}$ concentration. The permeate flux was significantly enhanced (i.e., $\left.76-107 \mathrm{~L} / \mathrm{m}^{2} \mathrm{~h}\right)$ with the addition of $(0.025 \mathrm{wt} . \%)$ ZnO-NPs [56]. 


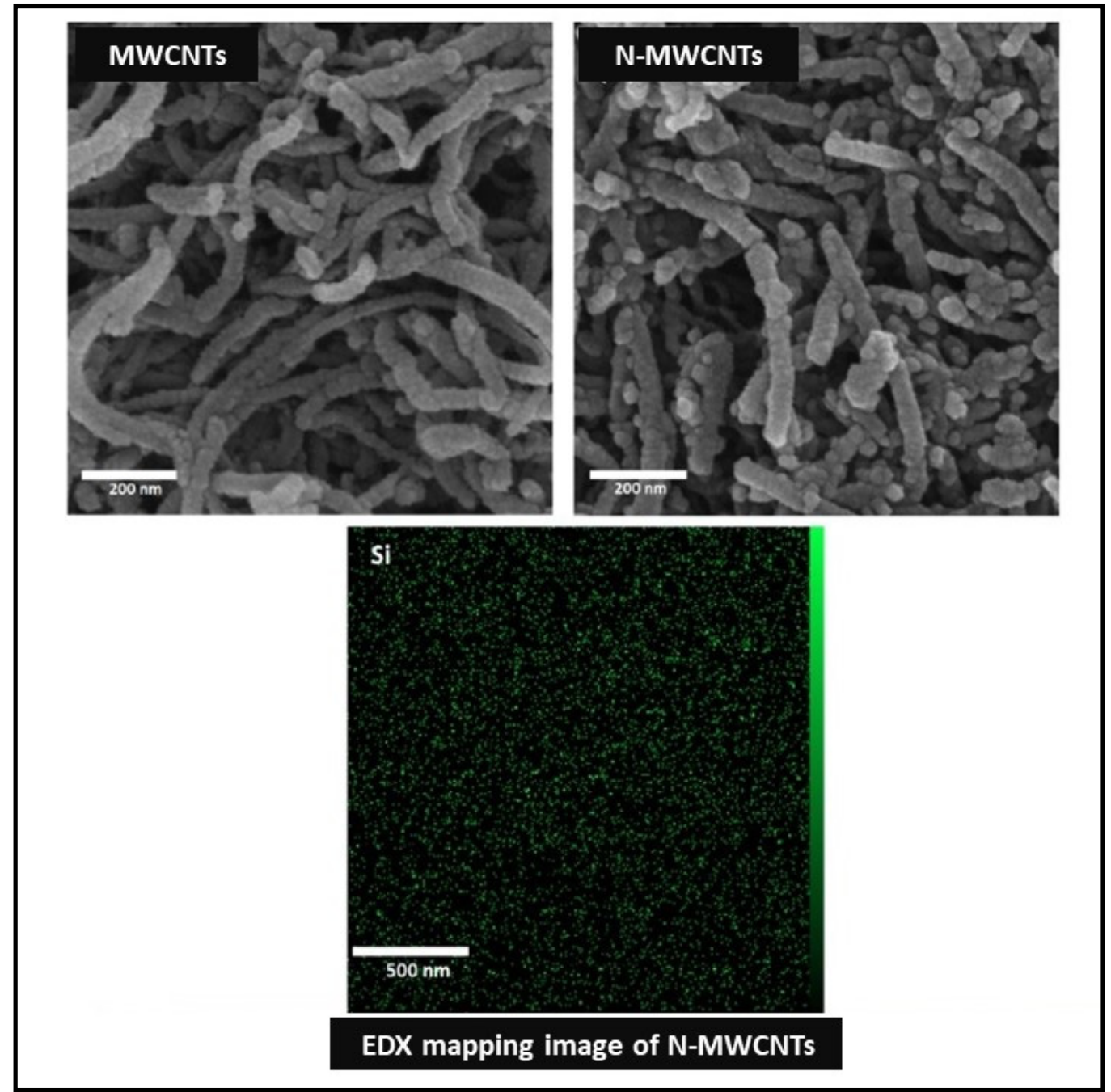

Figure 11. FESEM images of multiwall carbon nanotubes (MWCNTs) and N-MWCNTs. Reprinted with permission from ref. [21]. (C) 2019 Elsevier B.V.

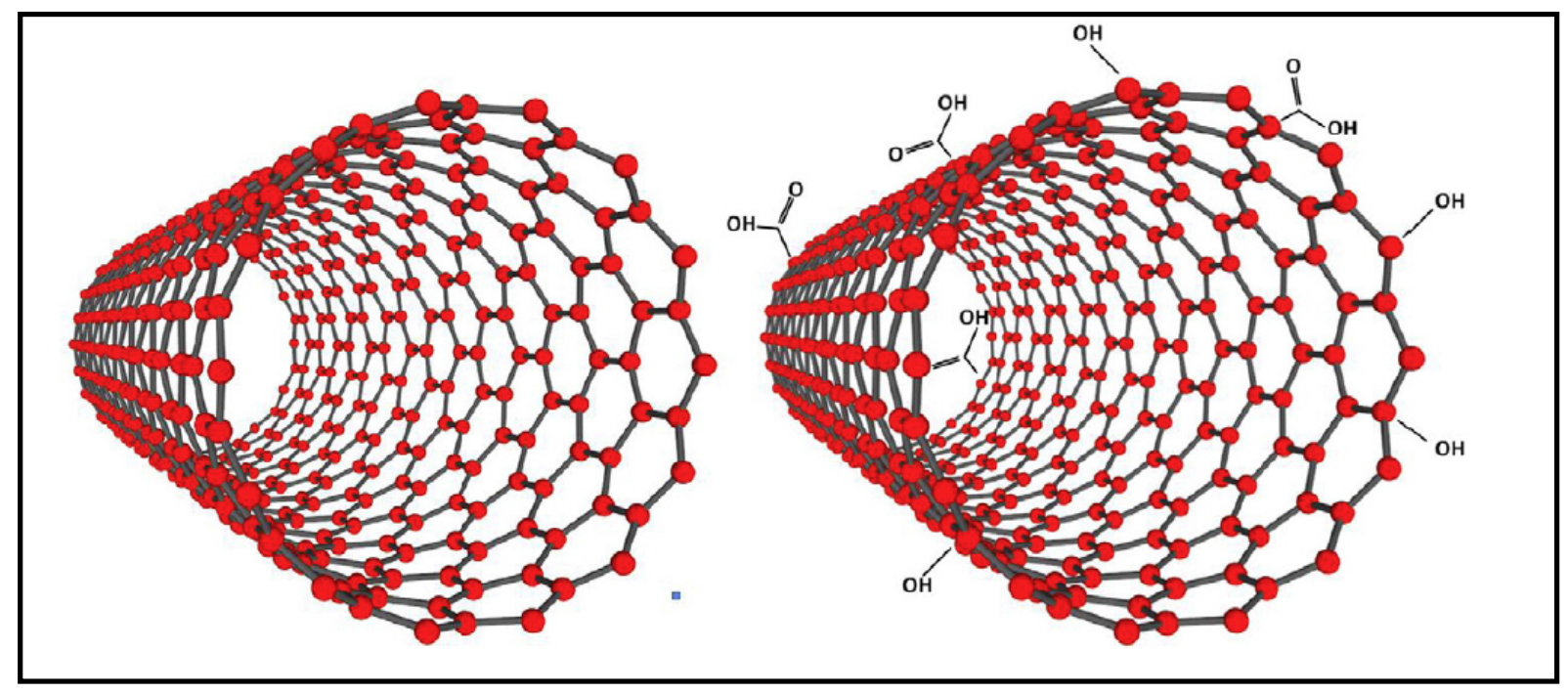

Figure 12. The oxidized multiwall carbon nanotubes (MWCNT) surface with acid mixture. Reprinted with permission from ref. [55]. (C) 2015 Elsevier B.V. 


\subsubsection{Ceramic Nanoparticles}

Ceramic nanoparticles consist mostly of oxides, carbides, phosphates, and metal carbonates and metalloids such as calcium, titanium, silicon, etc. Because of their chemical inertness and high heat resistance, it is possible to use them in a wide range of applications. Some examples of ceramic NPs are silica $\left(\mathrm{SiO}_{2}\right)$, titanium oxide $\left(\mathrm{TiO}_{2}\right)$, alumina $\left(\mathrm{Al}_{2} \mathrm{O}_{3}\right)$, hydroxyapatite (HA), and zirconia $\left(\mathrm{ZrO}_{2}\right)$ [54]. Several researchers utilized the ceramic NPs as an additive in polymer solution; for example, $\mathrm{Li}$ et al. used $\mathrm{SiO}_{2}-\mathrm{GO}$ to prepare a PVDF/ $/ \mathrm{SiO}_{2}-\mathrm{GO}$ nanohybrid; the TEM images of $\mathrm{GO}$ and $\mathrm{SiO}_{2}-\mathrm{GO}$ nanosheets are shown in Figure 13. The results showed that when the $(0.9 \mathrm{wt} . \%)$ concentration of $\mathrm{SiO}_{2}$-GO was added in the PVDF solution, the PVDF/SiO ${ }_{2}-\mathrm{GO}$ membrane (M-4) produced the lowest permeation flux $\left(182.6 \mathrm{~L} / \mathrm{m}^{2} \mathrm{~h}\right)$ and a higher removal $(91.7 \%)$. However, the over-high addition of $\mathrm{SiO}_{2} / \mathrm{GO}(1.2 \mathrm{wt} . \%)$ leads to the superior permeation flux $\left(679.1 \mathrm{~L} / \mathrm{m}^{2} \mathrm{~h}\right)$ [57]. The $\mathrm{SiO}_{2} / \mathrm{GO}$ nanohybrid particles were also used by $\mathrm{Zhu}$ et al. to prepare the PVDF/GO@SiO $/$ PVP membranes. The synthesis process, and the TEM and FESM images of nanoparticles $\mathrm{GO} @ S i O_{2}$, are shown in Figures 14 and 15, respectively. Figure 14 shows the synthesis process of nanoparticles $\mathrm{GO}^{-\mathrm{SiO}_{2}}$, and the $\mathrm{C}-\mathrm{O}-\mathrm{Si}$ structure was formed on the GO surface, which made it so that the nano-silca particles were firmly attached to the surface of $\mathrm{GO}$, and Figure 15 shows $\mathrm{SiO}_{2}$ particles as "black balls" and "white balls" which are dispersed homogeneously between the GO sheets. The PVDF/GO@SiO 2 /PVP membrane had much lower adhesion forces than PVDF/PVP membranes, implying that the $\mathrm{PVDF} / \mathrm{GO} @ \mathrm{SiO}_{2} / \mathrm{PVP}$ membrane has superior performance and antifouling capabilities among nanohybrid membranes. Due to the effects of $\mathrm{GO} / \mathrm{SiO}_{2}$ and PVP, the membrane had higher rejection, higher flux, and a great ability of antifouling [47].

The $\mathrm{TiO}_{2}$ had received most attention due to its ease of preparation, stability under harsh conditions, and commercial availability. It is an ideal material for preparing a composite membrane for oil/water separation, as it can achieve excellent oleophobicity and smooth water filtration that reduce membrane fouling. Wu et al. fabricated the membrane by assembling $\mathrm{TiO}_{2}$ nanotubes and GO nanosheets for oil/water separation, which improved the hydrophilicity, permeability, and anti-oil-fouling ability of the membranes [53].
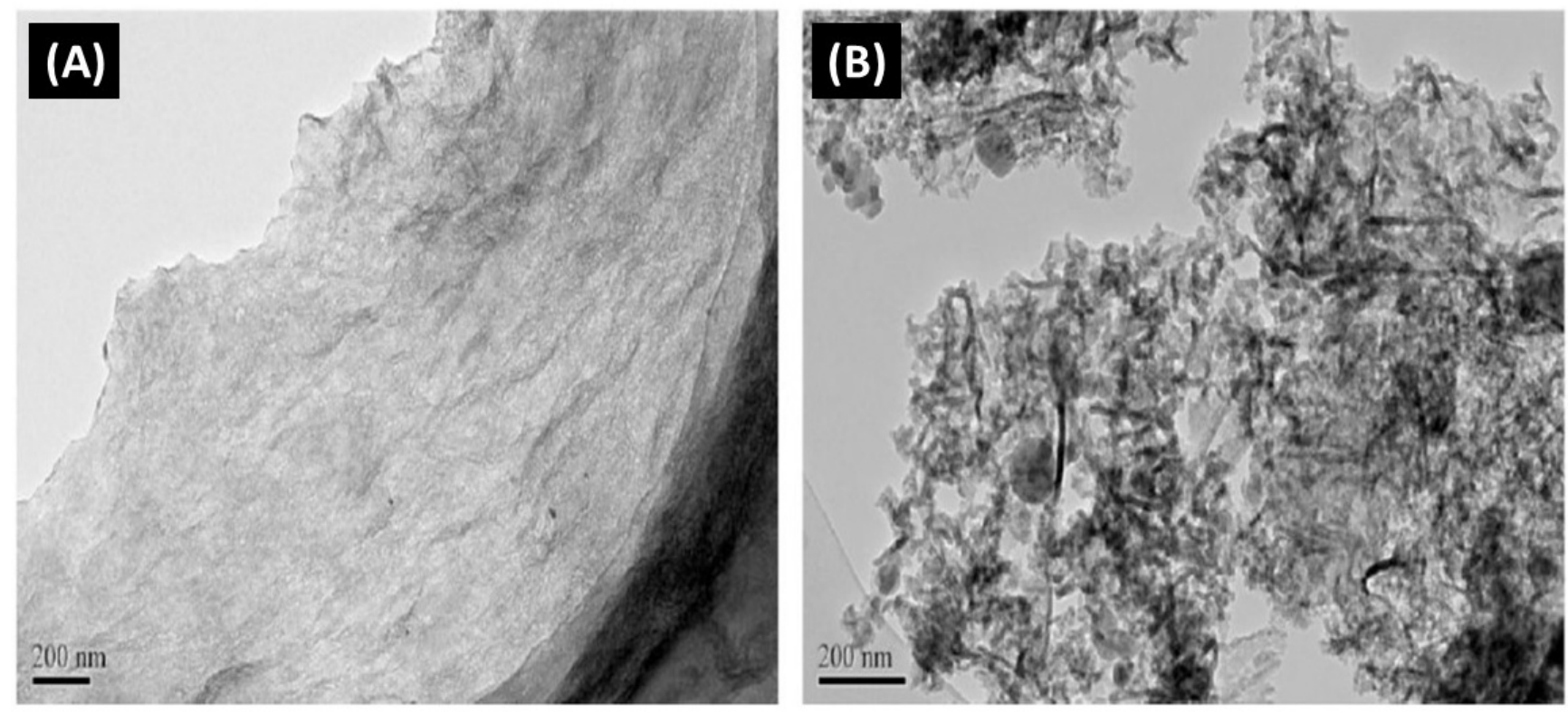

Figure 13. TEM image of (A) Graphene oxide (GO) nanosheets; (B) silicon dioxide-Graphene oxide $\left(\mathrm{SiO}_{2}-\mathrm{GO}\right)$ nanosheets. Reprinted with permission from ref. [57]. (C) 2016 Elsevier B.V. 


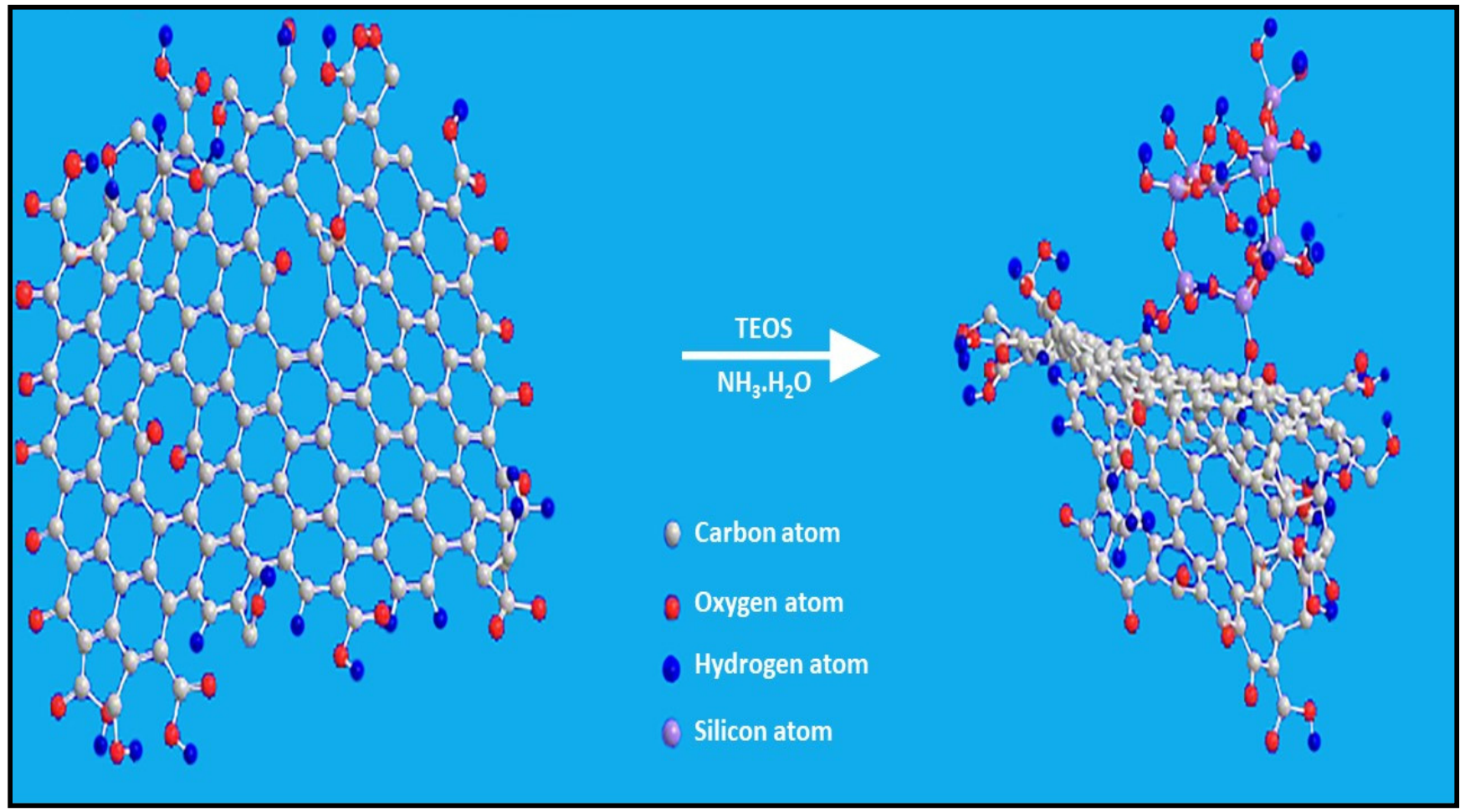

Figure 14. The synthesis process of nanoparticles silicon dioxide-Graphene oxide $\left(\mathrm{GO}-\mathrm{SiO}_{2}\right)$. Reprinted with permission from ref. [47]. (C) 2016 Elsevier B.V.

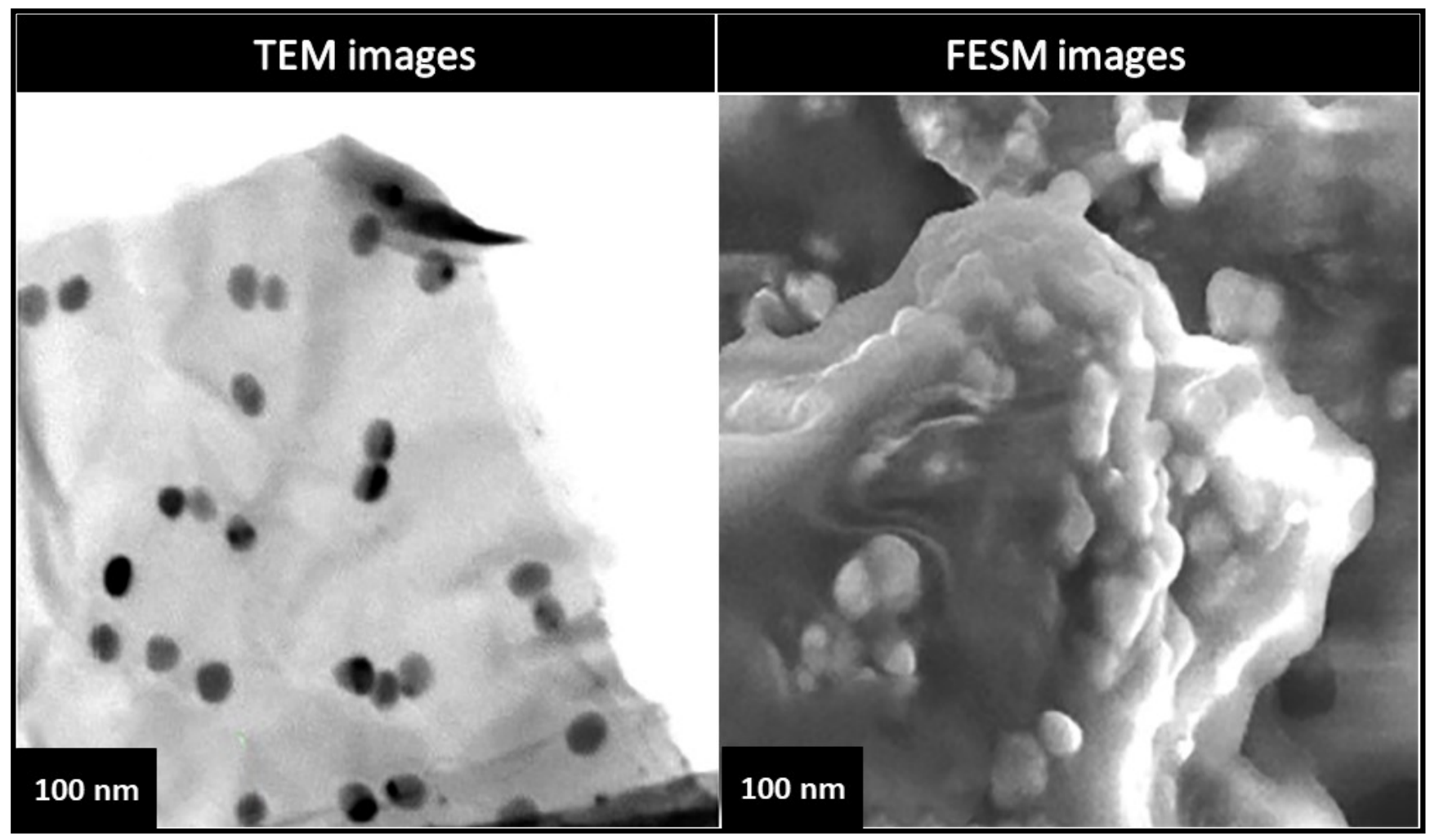

Figure 15. The TEM and FESM images of nanoparticles Graphene oxide-silicon dioxide $\left(\mathrm{GO}^{-} \mathrm{SiO}_{2}\right)$. Reprinted with permission from ref. [47]. (C) 2016 Elsevier B.V. 


\section{UF Membranes Applications in Oily Wastewater Treatment}

Among all applications of UF membrane, it has been widely applied for wastewater treatment especially for oily wastewater applications. Table 7 shows the summary of the UF membrane applications in oily wastewater. For example, the PVDF-based UF membrane was fabricated by Yuliwati et al., using $\mathrm{LiCl} . \mathrm{H}_{2} \mathrm{O}$ and $\mathrm{TiO}_{2}$ as embedded materials in PVDF solution for the application of refinery wastewater treatment. $\mathrm{TiO}_{2}$ with $(1.95 \%)$ and $(0.98 \%)$ of $\mathrm{LiCl} . \mathrm{H}_{2} \mathrm{O}$ in PVDF solution results in achieved water flux of $\left(82.5 \mathrm{~L} / \mathrm{m}^{2} \mathrm{~h}\right)$ and $(98.8 \%)$ oil rejection. The permeate flux reduced significantly when the $\mathrm{TiO}_{2}$ is excess over $(0.98 \%)$, due to poor dispersion of $\mathrm{TiO}_{2}$ in the membrane matrix [58]. A similar study using the PVDF membrane was conducted by Liu et al. In their study, the polyaniline PANI-modified PVDF membrane was utilized for oily wastewater treatment, and they found the water flux up to $3000 \mathrm{~L} / \mathrm{m}^{2} \mathrm{~h}$, high oil rejection, and high and steady flux of water permeation [59].

Moreover, the role of sulfonated polyphenyl sulfone (SPPSU) with the existence of the $\mathrm{MgO}$ nanoparticle for the oil/water emulsions treatment was investigated by Arumugham et al. [60]. The membrane made by using (25 wt.\%) SPPSU/MgO leads to an enhanced flux recovery ratio (FRR) to $(94.9 \%)$ due to the improvement of the hydrophilicity of the SPPSU/MgO membrane, which gives high oil rejection $(\geq 99 \%)$ and a water flux of $\left(234 \mathrm{~L} / \mathrm{m}^{2} \mathrm{~h}\right)[60]$.

In other studies carried out by Gohari et al. [61] and Kumar et al. [62], they used the PSf membrane for the treatment of an oil/water emulsion. Gohari et al. used hydrous manganese oxide (HAO) nanoparticles blended with the PSf membrane and enhanced the rejection $(\mathrm{R})$ to $(\sim 100 \%)$ and a water flux of $\left(1194 \mathrm{~L} / \mathrm{m}^{2} \mathrm{~h}\right)$ by using a HAO:PSf weight ratio of (2:1) [61]. However, Kumar et al. found that the impact of $10-15 \mathrm{wt} . \%$ in the CS on the PSf results in enhanced $\mathrm{R}$ with a reduced permeate flux due to the reduction in the porosity of the membrane [62].

Ahmad et al. fabricated the PVC/DMAc/bentonite membrane to enhance the performance of the PVC-based UF membrane for the treatment of oily wastewater with an oil concentration $200 \mathrm{ppm}$. At $6.0 \mathrm{wt} . \%$ bentonite in the CS, an enhanced PVC membrane performance with water flux $\left(186 \mathrm{~L} / \mathrm{m}^{2} \mathrm{~h}\right)$ was obtained due to the pore density, porosity, and hydrophilicity of the membrane [63].

In addition, PES MMM blended with hydrous manganese oxide (HMO) nanoparticles prepared by Gohari et al. for oily wastewater treatment (containing $1000 \mathrm{ppm}$ oil) found a high water flux of $\left(573.2 \mathrm{~L} / \mathrm{m}^{2} \mathrm{~h}\right)$, an oil rejection of ( 100\%), and a FRR of $(75.4 \%)$ [17].

The impact of varying concentrations of polyethylene glycol (PEG) on the morphology and performance of the PAN UF membrane was studied by Panda et al. [64]. At a PEG concentration of $(0.08 \mathrm{~g} / \mathrm{g})$, the water flux was enhanced to $\left(60 \mathrm{~L} / \mathrm{m}^{2} \mathrm{~h}\right)$, and the water flux reduced to $\left(50 \mathrm{~L} / \mathrm{m}^{2} \mathrm{~h}\right)$ with a further increase in PEG concentration [64]. 
Table 7. Shows the summary on the UF membrane applications in oily wastewater with membrane characterization and performance.

\begin{tabular}{|c|c|c|c|c|c|c|c|c|c|c|}
\hline \multirow[b]{2}{*}{ Polymer } & \multirow[b]{2}{*}{ Additives } & \multirow[b]{2}{*}{$\begin{array}{l}\text { Preparation } \\
\text { Technique }\end{array}$} & \multirow{2}{*}{$\begin{array}{c}\text { Oil } \\
\begin{array}{c}\text { Concentration } \\
(\mathrm{ppm})\end{array}\end{array}$} & \multicolumn{3}{|c|}{ Membrane Characterization } & \multicolumn{3}{|c|}{ Performance } & \multirow[b]{2}{*}{ Reference } \\
\hline & & & & Qi \% & $\begin{array}{l}\text { Contact } \\
\text { Angle }\end{array}$ & $\begin{array}{l}\text { Mean Pore } \\
\text { Size (nm) }\end{array}$ & $\underset{x\left(L / m^{2} h\right)}{F l u}$ & $\begin{array}{c}\text { Oil Rejection } \\
(\%)\end{array}$ & $\begin{array}{c}\text { Flux Recovery } \\
\text { Ratio (FRR) } \\
\text { (\%) }\end{array}$ & \\
\hline PVC & $\mathrm{TiO}_{2}-\mathrm{NPs}$ & - & 40.41 & 79.50 & $62.50^{\circ}$ & 77.00 & 116.00 & 96.30 & 89.90 & [4] \\
\hline PVDF & $\mathrm{LiCl} \cdot \mathrm{H}_{2} \mathrm{O} / \mathrm{SiO}_{2}$ & MMM & - & 85.41 & $50.00^{\circ}$ & 34.05 & 82.50 & 98.83 & 81.70 & [38] \\
\hline PVDF & $\mathrm{LiCl} \cdot \mathrm{H} 2 \mathrm{O} / \mathrm{TiO}_{2}$ & - & 17.00 & 85.41 & $47.33^{\circ}$ & - & 82.50 & 98.80 & 98.83 & [58] \\
\hline PPSU & SPPSU/MgO & NIPS & 1000.00 & 65.70 & $48.90^{\circ}$ & 24.00 & 234.00 & 99.00 & 94.90 & [60] \\
\hline PSf & $\mathrm{PVP} / \mathrm{HAO}$ & NIPS & $100.00-1000.00$ & 87.20 & $8.00^{\circ}$ & 48.98 & 1194.00 & $\approx 100.00$ & 67.00 & [61] \\
\hline PSf & PVP & NIPS & $100.00-400.00$ & 37.00 & $60.00^{\circ}$ & & 90.00 & $>90.00$ & - & [62] \\
\hline PVC & Bentonite & NIPS & 200.00 & 78.64 & $55.10^{\circ}$ & 118.90 & 412.00 & 97.00 & 81.97 & [63] \\
\hline PES & $\mathrm{PVP} / \mathrm{HMO}$ & NIPS & $100.00-1000.00$ & 87.90 & $16.40^{\circ}$ & 76.40 & 573.20 & 100.00 & 75.40 & [17] \\
\hline PAN & PEG & NIPS & $100.00-1000.00$ & - & - & - & 60.00 & 90.00 & - & [64] \\
\hline PES & $\mathrm{PDA} @ \mathrm{ZnFe}_{2} \mathrm{O}_{4} \mathrm{NCs}$ & NIPS & 500.00 & - & $52.00^{\circ}$ & 69.00 & $\sim 687.00$ & - & $\sim 82.50$ & [65] \\
\hline
\end{tabular}




\section{Conclusions}

Considerable efforts are being undertaken in finding effective technologies for oily wastewater treatment. Membrane technology is one of the promising methods for treating oily wastewater. Among all types of membrane technology, ultrafiltration (UF) is considered to be a versatile separation process and purification process. It is commonly used to treat oily wastewater with $<400 \mathrm{ppm}$ oil content and $<20 \mu \mathrm{m}$ oil droplet size.

However, its widespread use requires improving the characteristics of polymer membranes in order to solve the problems of clogging. For the separation of oily wastewater, the low-cost super hydrophilic polymeric UF membrane with enhanced morphology and mechanical strength is in high demand. As a result, low-cost PES, PVC, PSf, and other polymers may be employed as a basis polymer.

Several methods of polymer alterations were used to improve hydrophilicity, antifouling membrane ability, and oil rejection, including polymer blending, membrane surface modification, and the mixed membrane matrix. Since fouling usually occurs on the surface of membrane, surface modification is one of the most reliable and simple methods to apply. The main purpose of membrane modification is to provide high permeate flux and hydrophilicity, improve surface morphology, and thus improve membrane performance.

Moreover, another approach has been tried to improve the performance of polymeric membranes with a beneficial effect by using additives such as inorganic nanoparticles, hydrophilic polymers, and amphiphilic and grafted copolymers. Popular inorganic particles that have been repeatedly used to fabricate membranes are $\mathrm{SiO}_{2}, \mathrm{TiO}_{2}, \mathrm{Al}_{2} \mathrm{O}_{3}, \mathrm{MgO}, \mathrm{GO}$, etc. Their use in membranes has significantly improved their antifouling properties with respect to oil products.

This means that it is possible to prevent pollution of the environment with highly toxic oil products and to provide a source of clean water for recycling the water supply.

Author Contributions: Conceptualization, T.M.S., N.A.T., and Q.F.A.; methodology, E.S.A. and Q.F.A.; validation, T.M.S., Q.F.A., A.F. and N.A.T.; formal analysis, E.S.A.; investigation, E.S.A., and I.K.S.; data curation, E.S.A. and Q.F.A.; writing—original draft preparation, E.S.A. and Q.F.A.; writing—review and editing, T.M.S., Q.F.A., A.F. and N.A.T.; visualization, E.S.A. and Q.F.A.; supervision, T.M.S., N.A.T., and Q.F.A. All authors have read and agreed to the published version of the manuscript.

Funding: This research received no external funding.

Institutional Review Board Statement: Not applicable.

Informed Consent Statement: Not applicable.

Data Availability Statement: Not applicable.

Conflicts of Interest: The authors declare no conflict of interest.

\section{Abbreviations}

$\begin{array}{ll}\text { AFM } & \text { atomic force microscopy } \\ \text { APTES } & \text { 3-aminopropyltriethoxysilane } \\ \text { ATRP } & \text { Atom transfer radical polymerization } \\ \text { CNTs } & \text { Carbon nanotubes } \\ \text { DI } & \text { Deionized water } \\ \text { EDMA } & \text { Ethylene glycol dimethacrylate } \\ \text { EIPS } & \text { Evaporation induced phase inversion } \\ \text { FRR } & \text { Flux recovery ratio } \\ \text { F-MWCNTs } & \text { Functionalized-multiwall carbon nanotube } \\ \text { GMA } & \text { Glycidyl methacrylate } \\ \text { GO } & \text { Graphene oxide } \\ \text { HNTs } & \text { Halloysite nanotubes }\end{array}$




\begin{tabular}{|c|c|}
\hline $\mathrm{HMO}$ & Hydrous manganese oxide \\
\hline $\mathrm{HAO}$ & Hydrous manganese oxide \\
\hline $\mathrm{MgO}$ & Magnesium oxide \\
\hline MMM & Mixed matrix membrane \\
\hline MPD & M-phenylenediamine \\
\hline MWCNT & Multiwall carbon nanotubes \\
\hline NPs & Nanoparticles \\
\hline NMP & N-methyl-2-pyrrolidone \\
\hline NIPS & Non-solvent induced phase inversion \\
\hline PIP & Piperazine \\
\hline PDDA & Poly (diallyl-dimethylammonium chloride) \\
\hline $\mathrm{PDH}$ & Poly (dimethylaminoethyl methacrylate-co-2-hydroxyethyl methacrylate) \\
\hline PMMA & Poly (methyl methacrylate) \\
\hline PNIPAAm & Poly (N-isopropylacrylamide) \\
\hline PPEGMA & Poly (oligo ethylene glycol methacrylate) \\
\hline PSS & Poly (sodium 4-styrenesulfonate) \\
\hline PVA & Poly (vinylalcohol) \\
\hline PAN & Polyacrylonitrile \\
\hline PA & Polyamide \\
\hline PAI-SPEEK & Polyamide imide-sulfonated poly (ether keton) \\
\hline PANI & Polyaniline \\
\hline PES & Polyethersulfone \\
\hline PEI-CuNPs/PAA & Polyethyleneimine-CuNPs/poly(acrylic) acid \\
\hline PPSU & Polyphenylsulfone \\
\hline PSf & Polysulfone \\
\hline PVC & Polyvinyl chloride \\
\hline PVDF & Polyvinylidene fluoride \\
\hline PVP & Polyvinylpirrolidone \\
\hline $\mathrm{R}$ & Rejection coefficient \\
\hline SEM & Scanning electron microscopy \\
\hline $\mathrm{SiO}_{2}$ & Silicon dioxide \\
\hline SSLbL & Spray-and spin-assisted layer-by-layer \\
\hline SPPSU & Sulfonated polyphenyl sulfone \\
\hline SPC & Sulfonated polycarbonate \\
\hline TIPS & Thermally induced phase inversion \\
\hline TFC & Thin film composite \\
\hline $\mathrm{TiO}_{2}$ & Titanium dioxide \\
\hline TMC & Trimesoyl chloride \\
\hline UF & Ultrafiltration \\
\hline VIPS & Vapor induced phase inversion \\
\hline $\mathrm{ZnO}$ & Zinc oxide \\
\hline
\end{tabular}

\section{References}

1. Shakir, E. Assessment of nutrient content of raw water close to water treatment plants located in Baghdad City. Desalin. Water Treat. 2016, 57. [CrossRef]

2. Rajasekhar, T.; Trinadh, M.; Veera Babu, P.; Sainath, A.V.S.; Reddy, A.V.R. Oil-water emulsion separation using ultrafiltration membranes based on novel blends of poly(vinylidene fluoride) and amphiphilic tri-block copolymer containing carboxylic acid functional group. J. Memb. Sci. 2015. [CrossRef]

3. Mohammed, T.J.; Shakir, E. Effect of settling time, velocity gradient, and camp number on turbidity removal for oilfield produced water. Egypt. J. Pet. 2018, 27. [CrossRef]

4. Al-Ani, F.H.; Alsalhy, Q.F.; Raheem, R.S.; Rashid, K.T.; Figoli, A. Experimental investigation of the effect of implanting tio2-nps on pvc for long-term uf membrane performance to treat refinery wastewater. Membranes 2020, 10, 77. [CrossRef]

5. Mohammed, T.J.; Awad, E.S.; Ahmed, T.A. Oil Removal from Oilfield Produced Water, North Rumaila by Combination CoagulationFlocculation and Microfiltration Technique. Eng. Technol. J. 2019, 37, 204-208.

6. Litter, M.I.; Quici, N. Photochemical advanced oxidation processes for water and wastewater treatment. Recent Patents Eng. 2010, 4, 217-241. [CrossRef]

7. Ng, L.Y.; Mohammad, A.W.; Leo, C.P.; Hilal, N. Polymeric membranes incorporated with metal/metal oxide nanoparticles: A comprehensive review. Desalination 2013, 308, 15-33. [CrossRef] 
8. Ahmad, T.; Guria, C.; Mandal, A. A review of oily wastewater treatment using ultrafiltration membrane: A parametric study to enhance the membrane performance. J. Water Process Eng. 2020, 36, 101289. [CrossRef]

9. Jalal Sadiq, A.; Shabeeb, K.M.; Khalil, B.I.; Alsalhy, Q.F. Effect of embedding MWCNT-g-GO with PVC on the performance of PVC membranes for oily wastewater treatment. Chem. Eng. Commun. 2020. [CrossRef]

10. Padaki, M.; Surya Murali, R.; Abdullah, M.S.; Misdan, N.; Moslehyani, A.; Kassim, M.A.; Hilal, N.; Ismail, A.F. Membrane technology enhancement in oil-water separation. A review. Desalination 2015, 357, 197-207. [CrossRef]

11. Ihsanullah Carbon nanotube membranes for water purification: Developments, challenges, and prospects for the future. Sep. Purif. Technol. 2019, 209, 307-337. [CrossRef]

12. Wang, Q.; Cui, J.; Liu, S.; Gao, J.; Lang, J.; Li, C.; Yan, Y. Facile preparation of halloysite nanotube-modified polyvinylidene fluoride composite membranes for highly efficient oil/water emulsion separation. J. Mater. Sci. 2019. [CrossRef]

13. Zhang, W.; Shi, Z.; Zhang, F.; Liu, X.; Jin, J.; Jiang, L. Superhydrophobic and superoleophilic PVDF membranes for effective separation of water-in-oil emulsions with high flux. Adv. Mater. 2013. [CrossRef]

14. Zhang, X.; Wang, Y.; Liu, Y.; Xu, J.; Han, Y.; Xu, X. Preparation, performances of PVDF/ZnO hybrid membranes and their applications in the removal of copper ions. Appl. Surf. Sci. 2014, 316, 333-340. [CrossRef]

15. Shi, H.; He, Y.; Pan, Y.; Di, H.; Zeng, G.; Zhang, L.; Zhang, C. A modified mussel-inspired method to fabricate TiO 2 decorated superhydrophilic PVDF membrane for oil/water separation. J. Memb. Sci. 2016, 506, 60-70. [CrossRef]

16. Ejaz Ahmed, F.; Lalia, B.S.; Hilal, N.; Hashaikeh, R. Underwater superoleophobic cellulose/electrospun PVDF-HFP membranes for efficient oil/water separation. Desalination 2014. [CrossRef]

17. Gohari, R.J.; Halakoo, E.; Lau, W.J.; Kassim, M.A.; Matsuura, T.; Ismail, A.F. Novel polyethersulfone (PES)/hydrous manganese dioxide (HMO) mixed matrix membranes with improved anti-fouling properties for oily wastewater treatment process. RSC Adv. 2014, 4, 17587-17596. [CrossRef]

18. Salahi, A.; Mohammadi, T.; Mosayebi Behbahani, R.; Hemmati, M. Asymmetric polyethersulfone ultrafiltration membranes for oily wastewater treatment: Synthesis, characterization, ANFIS modeling, and performance. J. Environ. Chem. Eng. 2015. [CrossRef]

19. Li, J.; Wang, Q.; Deng, L.; Kou, X.; Tang, Q.; Hu, Y. Fabrication and characterization of carbon nanotubes-based porous composite forward osmosis membrane: Flux performance, separation mechanism, and potential application. J. Memb. Sci. 2020. [CrossRef]

20. Alkindy, M.B.; Naddeo, V.; Banat, F.; Hasan, S.W. Synthesis of polyethersulfone (PES) $/ \mathrm{GO}_{-} \mathrm{SiO}_{2}$ mixed matrix membranes for oily wastewater treatment. Water Sci. Technol. 2020. [CrossRef] [PubMed]

21. Zarghami, S.; Mohammadi, T.; Sadrzadeh, M.; Van der Bruggen, B. Bio-inspired anchoring of amino-functionalized multi-wall carbon nanotubes (N-MWCNTs) onto PES membrane using polydopamine for oily wastewater treatment. Sci. Total Environ. 2020. [CrossRef]

22. Chakrabarty, B.; Ghoshal, A.K.; Purkait, M.K. Ultrafiltration of stable oil-in-water emulsion by polysulfone membrane. J. Memb. Sci. 2008. [CrossRef]

23. Ahmad, A.L.; Majid, M.A.; Ooi, B.S. Functionalized PSf $/ \mathrm{SiO}_{2}$ nanocomposite membrane for oil-in-water emulsion separation. Desalination 2011, 268, 266-269. [CrossRef]

24. Saadati, J.; Pakizeh, M. Separation of oil/water emulsion using a new PSf/pebax/F-MWCNT nanocomposite membrane. J. Taiwan Inst. Chem. Eng. 2017, 71, 265-276. [CrossRef]

25. Modi, A.; Bellare, J. Efficiently improved oil/water separation using high flux and superior antifouling polysulfone hollow fiber membranes modified with functionalized carbon nanotubes/graphene oxide nanohybrid. J. Environ. Chem. Eng. 2019. [CrossRef]

26. Ahmad, T.; Guria, C.; Mandal, A. Optimal synthesis of high fouling-resistant PVC-based ultrafiltration membranes with tunable surface pore size distribution and ultralow water contact angle for the treatment of oily wastewater. Sep. Purif. Technol. 2021, 257, 117829. [CrossRef]

27. Salahi, A.; Abbasi, M.; Mohammadi, T. Permeate flux decline during UF of oily wastewater: Experimental and modeling. Desalination 2010. [CrossRef]

28. Zhang, F.; Gao, S.; Zhu, Y.; Jin, J. Alkaline-induced superhydrophilic/underwater superoleophobic polyacrylonitrile membranes with ultralow oil-adhesion for high-efficient oil/water separation. J. Memb. Sci. 2016. [CrossRef]

29. Alsalhy, Q.F. Hollow fiber ultrafiltration membranes prepared from blends of poly (vinyl chloride) and polystyrene. Desalination 2012. [CrossRef]

30. Yuan, T.; Meng, J.; Hao, T.; Wang, Z.; Zhang, Y. A scalable method toward superhydrophilic and underwater superoleophobic PVDF membranes for effective oil/water emulsion separation. ACS Appl. Mater. Interfaces 2015. [CrossRef] [PubMed]

31. Ismail, N.H.; Salleh, W.N.W.; Ismail, A.F.; Hasbullah, H.; Yusof, N.; Aziz, F.; Jaafar, J. Hydrophilic polymer-based membrane for oily wastewater treatment: A review. Sep. Purif. Technol. 2020, 233, 116007. [CrossRef]

32. Masuelli, M.; Marchese, J.; Ochoa, N.A. SPC/PVDF membranes for emulsified oily wastewater treatment. J. Memb. Sci. 2009. [CrossRef]

33. Zhu, Y.; Xie, W.; Zhang, F.; Xing, T.; Jin, J. Superhydrophilic In-Situ-Cross-Linked Zwitterionic Polyelectrolyte/PVDF-Blend Membrane for Highly Efficient Oil/Water Emulsion Separation. ACS Appl. Mater. Interfaces 2017. [CrossRef] [PubMed]

34. Johari, A.; Razmjouei, M.; Mansourizadeh, A.; Emadzadeh, D. Fabrication of blend hydrophilic polyamide imide (Torlon $\left.{ }^{\circledR}\right)-$ sulfonated poly (ether ether ketone) hollow fiber membranes for oily wastewater treatment. Polym. Test. 2020. [CrossRef] 
35. Rajaeian, B.; Heitz, A.; Tade, M.O.; Liu, S. Improved separation and antifouling performance of PVA thin film nanocomposite membranes incorporated with carboxylated $\mathrm{TiO}_{2}$ nanoparticles. J. Memb. Sci. 2015. [CrossRef]

36. Wandera, D.; Wickramasinghe, S.R.; Husson, S.M. Modification and characterization of ultrafiltration membranes for treatment of produced water. J. Memb. Sci. 2011. [CrossRef]

37. Masuelli, M.A.; Grasselli, M.; Marchese, J.; Ochoa, N.A. Preparation, structural and functional characterization of modified porous PVDF membranes by $\gamma$-irradiation. J. Memb. Sci. 2012. [CrossRef]

38. Yuliwati, E.; Ismail, A.F. Effect of additives concentration on the surface properties and performance of PVDF ultrafiltration membranes for refinery produced wastewater treatment. Desalination 2011. [CrossRef]

39. Ong, C.S.; Lau, W.J.; Goh, P.S.; Ismail, A.F. Preparation and characterization of PVDF-TiO ${ }_{2}$ composite membranes blended with different Mw of PVP for oily wastewater treatment using submerged membrane system. J. Teknol. Sci. Eng. 2014. [CrossRef]

40. Ong, C.S.; Lau, W.J.; Goh, P.S.; Ng, B.C.; Ismail, A.F. Preparation and characterization of PVDF-PVP-TiO 2 composite hollow fiber membranes for oily wastewater treatment using submerged membrane system. Desalin. Water Treat. 2015. [CrossRef]

41. Yi, X.S.; Yu, S.L.; Shi, W.X.; Sun, N.; Jin, L.M.; Wang, S.; Zhang, B.; Ma, C.; Sun, L.P. The influence of important factors on ultrafiltration of oil/water emulsion using PVDF membrane modified by nano-sized $\mathrm{TiO}_{2} / \mathrm{Al}_{2} \mathrm{O}_{3}$. Desalination 2011. [CrossRef]

42. Shen, J.N.; Yu, C.C.; Ruan, H.M.; Gao, C.J.; Van der Bruggen, B. Preparation and characterization of thin-film nanocomposite membranes embedded with poly(methyl methacrylate) hydrophobic modified multiwalled carbon nanotubes by interfacial polymerization. J. Memb. Sci. 2013. [CrossRef]

43. Marquez, J.A.D.; Ang, M.B.M.Y.; Doma, B.T.; Huang, S.H.; Tsai, H.A.; Lee, K.R.; Lai, J.Y. Application of cosolvent-assisted interfacial polymerization technique to fabricate thin-film composite polyamide pervaporation membranes with PVDF hollow fiber as support. J. Memb. Sci. 2018. [CrossRef]

44. Ma, W.; Soroush, A.; Van Anh Luong, T.; Brennan, G.; Rahaman, M.S.; Asadishad, B.; Tufenkji, N. Spray- and spin-assisted layer-by-layer assembly of copper nanoparticles on thin-film composite reverse osmosis membrane for biofouling mitigation. Water Res. 2016. [CrossRef] [PubMed]

45. Liu, L.; Son, M.; Chakraborty, S.; Bhattacharjee, C.; Choi, H. Fabrication of ultra-thin polyelectrolyte/carbon nanotube membrane by spray-assisted layer-by-layer technique: Characterization and its anti-protein fouling properties for water treatment. Desalin. Water Treat. 2013, 51, 6194-6200. [CrossRef]

46. Yang, X.; He, Y.; Zeng, G.; Chen, X.; Shi, H.; Qing, D.; Li, F.; Chen, Q. Bio-inspired method for preparation of multiwall carbon nanotubes decorated superhydrophilic poly(vinylidene fluoride) membrane for oil/water emulsion separation. Chem. Eng. J. 2017. [CrossRef]

47. Zhu, Z.; Jiang, J.; Wang, X.; Huo, X.; Xu, Y.; Li, Q.; Wang, L. Improving the hydrophilic and antifouling properties of polyvinylidene fluoride membrane by incorporation of novel nanohybrid $\mathrm{GO} @ \mathrm{SiO}_{2}$ particles. Chem. Eng. J. 2017. [CrossRef]

48. Aerts, P.; Genné, I.; Leysen, R.; Jacobs, P.A.; Vankelecom, I.F.J. The role of the nature of the casting substrate on the properties of membranes prepared via immersion precipitation. J. Memb. Sci. 2006. [CrossRef]

49. Wu, H.; Tang, B.; Wu, P. Novel ultrafiltration membranes prepared from a multi-walled carbon nanotubes/polymer composite. J. Memb. Sci. 2010, 362, 374-383. [CrossRef]

50. Mansourizadeh, A.; Ismail, A.F.; Abdullah, M.S.; Ng, B.C. Preparation of polyvinylidene fluoride hollow fiber membranes for $\mathrm{CO} 2$ absorption using phase-inversion promoter additives. J. Memb. Sci. 2010. [CrossRef]

51. Sakinah, A.M.M.; Ismail, A.F.; Illias, R.M.; Zularisam, A.W.; Hassan, O.; Matsuura, T. Cyclodextrin production in hollow fiber membrane reactor system: Effect of substrate preparation. Sep. Purif. Technol. 2008. [CrossRef]

52. Kim, J.; Van der Bruggen, B. The use of nanoparticles in polymeric and ceramic membrane structures: Review of manufacturing procedures and performance improvement for water treatment. Environ. Pollut. 2010, 158, 2335-2349. [CrossRef]

53. Wu, Z.; Zhang, C.; Peng, K.; Wang, Q.; Wang, Z. Hydrophilic/underwater superoleophobic graphene oxide membrane intercalated by $\mathrm{TiO} 2$ nanotubes for oil/water separation. Front. Environ. Sci. Eng. 2018, 12, 15. [CrossRef]

54. Khan, I.; Saeed, K.; Khan, I. Nanoparticles: Properties, applications and toxicities. Arab. J. Chem. 2019, 12, 908-931. [CrossRef]

55. Moslehyani, A.; Ismail, A.F.; Othman, M.H.D.; Matsuura, T. Design and performance study of hybrid photocatalytic reactorPVDF/MWCNT nanocomposite membrane system for treatment of petroleum refinery wastewater. Desalination 2015, 363, 99-111. [CrossRef]

56. Alsalhy, Q.F.; Ali, J.M.; Abbas, A.A.; Rashed, A.; van der Bruggen, B.; Balta, S. Enhancement of poly(phenyl sulfone) membranes with ZnO nanoparticles. Desalin. Water Treat. 2013. [CrossRef]

57. Li, Z.-K.; Lang, W.-Z.; Miao, W.; Yan, X.; Guo, Y.-J. Preparation and properties of PVDF/SiO $@$ @ GO nanohybrid membranes via thermally induced phase separation method. J. Memb. Sci. 2016, 511, 151-161. [CrossRef]

58. Yuliwati, E.; Ismail, A.F.; Matsuura, T.; Kassim, M.A.; Abdullah, M.S. Effect of modified pvdf hollow fiber submerged ultrafiltration membrane for refinery wastewater treatment. Desalination 2011. [CrossRef]

59. Liu, M.; Li, J.; Guo, Z. Polyaniline coated membranes for effective separation of oil-in-water emulsions. J. Colloid Interface Sci. 2016. [CrossRef]

60. Arumugham, T.; Kaleekkal, N.J.; Rana, D.; Doraiswamy, M. Separation of oil/water emulsions using nano MgO anchored hybrid ultrafiltration membranes for environmental abatement. J. Appl. Polym. Sci. 2016, 133. [CrossRef] 
61. Jamshidi Gohari, R.; Korminouri, F.; Lau, W.J.; Ismail, A.F.; Matsuura, T.; Chowdhury, M.N.K.; Halakoo, E.; Jamshidi Gohari, M.S. A novel super-hydrophilic PSf/HAO nanocomposite ultrafiltration membrane for efficient separation of oil/water emulsion. Sep. Purif. Technol. 2015. [CrossRef]

62. Kumar, S.; Nandi, B.K.; Guria, C.; Mandal, A. Oil removal from produced water by ultrafiltration using polysulfone membrane. Brazilian J. Chem. Eng. 2017. [CrossRef]

63. Ahmad, T.; Guria, C.; Mandal, A. Synthesis, characterization and performance studies of mixed-matrix poly (vinyl chloride)bentonite ultrafiltration membrane for the treatment of saline oily wastewater. Process Saf. Environ. Prot. 2018, 116, 703-717. [CrossRef]

64. Panda, S.R.; Bhandaru, N.; Mukherjee, R.; De, S. Ultrafiltration of oily waste water: Contribution of surface roughness in membrane properties and fouling characteristics of polyacrylonitrile membranes. Can. J. Chem. Eng. 2015. [CrossRef]

65. Kallem, P.; Othman, I.; Ouda, M.; Hasan, S.W.; AlNashef, I.; Banat, F. Polyethersulfone hybrid ultrafiltration membranes fabricated with polydopamine modified $\mathrm{ZnFe} 2 \mathrm{O} 4$ nanocomposites: Applications in humic acid removal and oil/water emulsion separation. Process Saf. Environ. Prot. 2021, 148, 813-824. [CrossRef] 